\title{
Jueces que dicen el derecho: Levene y Maier reformadores de la justicia penal argentina
}

\author{
Judges Who Speak the Law: Levene and Maier \\ reformers of Argentine Criminal Justice
}

Juízes que dizem o direito: Levene e Maier reformadores da justiça penal Argentina

Julieta Mira*

\section{Resumen}

Ricardo Levene (h.) y Julio Maier se destacaron de forma simultánea como jueces, juristas y profesores de derecho penal, $\mathrm{y}$ fueron quienes en el siglo XX bregaron en la Argentina por la reforma del primer Código de Procedimientos en lo Criminal para la Justicia Federal, que había sido promulgado en el año 1888. En este trabajo se presentan las trayectorias de ambos "reformadores" para hacer visible el impacto tanto de su experiencia como de la internacionalización en la gesta y la promoción de la transformación legislativa en materia penal a nivel local con su consecuente incidencia en la región latinoamericana. Se muestra, en particular, su apuesta por el derecho penal comparado y su circulación transnacional, tanto en su formación académica como en el trabajo profesional asociado fuertemente a la reforma de la justicia penal. La metodología de investigación es cualitativa, llevada a cabo por medio de entrevistas y el relevamiento de fuentes secundarias. En las conclusiones, se enfatiza el aporte de abordar las trayectorias de los expertos en derecho de modo de apreciar el impacto de la transnacionalización en la conformación de redes profesionales y la circulación de las ideas jurídicas, en este caso, en la constitución de los procesos de reforma procesal penal federal y la consecuente transformación del modelo de enjuiciamiento estatal.
Palabras clave: capital simbólico, circulación de las ideas jurídicas, jueces, saber, trayectorias. de San Martín, Provincia de Buenos Aires, Argentina. E-mail: jmira@unsam.edu.ar. 


\begin{abstract}
Ricardo Levene (h.) and Julio Maier were simultaneously renowned judges, jurists and criminal law professors who, in the 20th century, fought in Argentina to reform the first Código de Procedimientos en lo Criminal -National Code of Criminal Procedure-, which had been issued in 1888. This paper presents both "reformers"' careers to show the impact of both their expertise and internationalization on performing and promoting criminal legislative transformation at a local level, and its resulting influence on the Latin American region. In particular, it highlights their investment in comparative criminal law and their transnational circulation, both in their educational and professional careers, strongly associated with criminal justice reform. The research methodology is qualitative by means of interviews and the gathering of secondary sources. The conclusions point out the contribution of addressing the personal trajectories of legal experts in order to understand the impact of transnationalization and the construction of professional networks in the circulation of legal ideas, in this case, in the constitution of processes within the national criminal procedure reform and the subsequent transformation of the state prosecution model.
\end{abstract}

\section{RESUMO}

Ricardo Levene (h.) e Julio Maier se destacaram simultaneamente como juízes, juristas e professores de direito penal e foram quem no século XX lutaram na Argentina pela reforma do primeiro Código de Procedimento Criminal para a Justiça Federal, que havia sido promulgado em 1888. Neste trabalho são apresentadas as trajetórias de ambos "reformadores" a fim de tornar visível o impacto tanto de sua experiência quanto da internacionalização no desenvolvimento e promoção da transformação legislativa em matéria penal em nível local com seu consequente impacto na região latino-americana. É apresentada, em particular, sua aposta pelo direito penal comparado e sua circulação transnacional, tanto em sua formação acadêmica como no trabalho profissional fortemente associado à reforma da justiça penal. A metodologia de investigação é qualitativa, através da realização de entrevistas e da pesquisa em fontes secundárias. Nas conclusões, enfatiza-se a contribuição de abordar as trajetórias dos especialistas em direito para apreciar o impacto da transnacionalização na formação de redes profissionais e na circulação das ideias jurídicas, neste caso, na constituição dos processos de reforma processual penal federal e a consequente transformação de seu modelo estatal.
Keywords: symbolic capital, circulation of legal ideas, judges, expertise, trajectories.

Palavras-chave: capital simbólico, circulação de ideias jurídicas, juízes, saber, trajetórias. 
La reforma del Derecho penal es tan antigua como el Derecho penal mismo. Más el gran movimiento internacional que tiene lugar en el presente en pos de su renovación, no encuentra parangón en la historia.

El movimiento internacional de reforma del Derecho penal, constituye un signo del cambio espiritual que se ha producido desde la mitad del presente siglo en la actitud ante la criminalidad y ante las posibilidades y métodos para combatirla.

HANS-HEINRICH JESCHECK (1982)

\title{
1. Introducción: La reforma procesal penal federal argentina desde sus protagonistas
}

\begin{abstract}
En este artículo $^{2}$ se propone comprender el caso de la reforma procesal penal federal en la Argentina desde una mirada sociológica, por medio de reconstruir las trayectorias de los principales promotores de los proyectos de nuevos códigos en dicha materia. Los proclamados "padres" ${ }^{3}$ de la reforma han sido destacados jueces, juristas y profesores de derecho penal. Se trata de Ricardo Levene (h.) ${ }^{4}$ oriundo de la ciudad de
\end{abstract}

\footnotetext{
2 Este trabajo fue posible gracias a mi posición de investigadora y becaria postdoctoral en el International Research Group on Authoritarianism and Counter-Strategies (IRGAC) de Rosa Luxemburg Stiftung (Berlín, Alemania), con sede en la Universidad Nacional de Mar del Plata, Provincia de Buenos Aires, Argentina. El presente artículo se enmarca en la investigación realizada entre los años 2009 y 2014 para mi tesis doctoral titulada: Una promesa de democratización. Activismo, política y expertise jurídica en el proceso de reforma de la justicia penal en la Argentina, dirigida por la Prof. Dra. Virginia Vecchioli en el programa doctoral de la Facultad de Ciencias Sociales de la Universidad de Buenos Aires (UBA). La antedicha tesis recibió la Mención Especial (segundo premio) en el año 2019, por decisión de un jurado internacional, en el Concurso Nacional de Tesis organizado por la UBA y EUDEBA. Le agradezco a los evaluadores anónimos por su constructivo aporte y su desafiante impulso para profundizar aspectos de este texto en diálogo con diversas tradiciones de pensamiento en las que se construye esta reflexión.

3 Como convención a lo largo de este artículo las palabras entre comillas refieren a expresiones de los propios agentes en el campo, es decir, representa la voz nativa que consiste en un concepto de la antropología para dar cuenta de las expresiones de los nativos o habitantes de los lugares donde llegaban los etnógrafos en sus viajes a lugares exóticos. Estos términos nativos se diferencian de las categorías teóricas que se escriben en cursivas, al igual que títulos, conceptos y/o palabras en otros idiomas. Se menciona asimismo que con el fin de evidenciar la dimensión internacional las obras, las revistas y las instituciones de diversos países referidas a lo largo del artículo se titulan o denominan en su lengua original.

$4 \quad$ Hijo del afamado historiador del derecho Ricardo Levene, motivo por el cual se presentaba y firmaba sus obras como Ricardo Levene (h.), al ser conocido en el mundo del derecho de este modo en lo sucesivo así se escribirá su nombre. Se aclara que a continuación se presenta también al hijo de este protagonista del artículo que lleva el mismo nombre que su padre y abuelo, por este motivo es conocido como Ricardo Levene nieto (n.).
} 
Buenos Aires (1914-2000) y de Julio Maier nacido en la Provincia de Córdoba (1939). El primero de ellos integró en dos oportunidades la Corte Suprema de Justicia de la Nación, mientras que el segundo se desempeñó como juez en el Tribunal Superior de Justicia de la Ciudad Autónoma de Buenos Aires. El análisis de las trayectorias de estos reconocidos "reformadores", en particular, facilita la observación del impacto en el cambio normativo de la circulación internacional de las ideas del derecho penal, lo que se traduce en la transformación de las reglas estatales del enjuiciamiento penal en la Argentina que ha conquistado influencia en otros países latinoamericanos.

Con la meta mencionada se funda el análisis de esta investigación con una perspectiva reflexiva (Madsen, 2006; Vecchioli, 2011) sobre las ciencias sociales, que invita a tomar distancia de los análisis de los actores, o bien en los agentes, para poder comprender de forma crítica el fenómeno investigado y aportar otras dimensiones analíticas sobre el derecho ${ }^{5}$. Esta peculiar mirada procura, al mismo tiempo, contribuir a la comprensión del derecho como un hecho o un fenómeno social digno de un abordaje sociológico. Este giro convierte al derecho en un objeto de estudio sociológico, para lo que es precisa una investigación empírica que permita aportar tanto a la consolidación como a la autonomía del campo de la sociología política del derecho (Engelmann, 2006). En este terreno se inscribe la investigación que aquí se expone. Al mismo tiempo, este trabajo se propone puntualmente contribuir al desarrollo de los estudios sociales de los jueces y del poder judicial en la región latinoamericana.

\footnotetext{
$5 \quad$ Sin duda que el abordaje sociológico centrado en los agentes y sus prácticas brinda elementos que ofrecen la potencialidad de complementarse y dialogar con las nutridas producciones de la historia del derecho y de las ideas jurídicas que tratan aspectos del tema en estudio (Cesano, 2017; Levaggi, 2012; Tau Anzoátegui, 1977a, 1977b). Sin embargo, es preciso destacar que el tratamiento aquí propuesto de análisis de la reforma de la justicia penal no se enfoca en la dimensión normativa que ha sido desarrollada de forma destacada en numerosos análisis de estos procesos por los propios impulsores de estas transformaciones jurídicas (Binder, 1993; Levene, 1993; Maier, 1987, 1989, 1996). A la hora de retomar estas fuentes, desde un análisis sociológico, se requiere considerar la posición en el debate público de los abogados que dan cuenta de estos fenómenos para comprender por qué dicen lo que dicen, sus disputas y su activismo en el movimiento de reforma del derecho penal. En otras palabras, para pensar sociológicamente el objeto de la reforma de la justicia penal precisamos herramientas sociológicas que dificilmente se encuentran en otras disciplinas que abordan esta cuestión a partir de sus propios puntos de vista, desde luego válidos y relevantes aunque diferentes.
} 
Esta apuesta intelectual está inspirada profundamente en la sociología del derecho francesa iniciada por Pierre Bourdieu (2000) y sus discípulos, entre ellos, Alain Bancaud e Yves Dezalay (1984). La llave heurística para el entendimiento de los jueces y la justicia la aportó Bourdieu (2000) cuando señaló que los profesionales del derecho generan "la necesidad de sus propios servicios al constituir en problemas jurídicos los problemas expresados en el lenguaje ordinario" (p. 190), lo cual logran por medio del ejercicio de la traducción del lenguaje ordinario al jurídico. "Nada es menos natural que la 'necesidad jurídica' o el sentimiento de injusticia que puede llevar a recurrir a los servicios de un profesional: se sabe, en efecto, que la sensibilidad hacia la injusticia o la capacidad de percibir una experiencia como injusta no está uniformemente repartida y depende estrechamente de la posición que se ocupa en el espacio social", afirmó Bourdieu (2000, p. 189). La necesidad jurídica, Bourdieu (2000) prosigue, "supone un trabajo de construcción de realidad social [las cursivas me pertenecen] que incumbre, en gran parte, a los profesionales" (pp. 189-190). Así, Bourdieu sostiene que el campo jurídico opera como un principio de construcción de realidad una vez que las situaciones ordinarias son redefinidas de acuerdo con su definición jurídica, descubriendo derechos e injusticias. En suma, al poner el foco en este grupo profesional de jueces, se procura presentar la fuerza del derecho (Bourdieu, 2000) que se invierte en configurar la causa (Gaïti e Israël 2003; Israël 2001) ${ }^{6}$ de la justicia y sus prácticas, teniendo en cuenta que son los jueces quienes se encuentran facultados para decir el derecho (Bourdieu, 1991, 2000).

En el marco de la estrategia necesaria para contribuir con la sociología política de los jueces y del poder judicial no sería necesario ahondar en las concepciones o en los pensamientos jurídicos de los "reformadores", ni tampoco evaluar sus propuestas de reforma. En cambio, esta meta sí requiere indagar, en términos sociológicos, quiénes son estos agentes fundamentales de la reforma jurídica y cómo actúan, lo cual permite explorar cómo pudieron realizar su contribución al derecho desde una lógica centrada en el activismo jurídico (Agrikoliansky, 2001; Fillieule, 2001; Sawicki \& Siméant, 2009). Desde este enfoque, se

Por causa se comprende a un conjunto de intereses que los agentes buscan hacer valer en la esfera pública que refieren a un sentido político que se construye históricamente y que por ese motivo precisa ser explicado. 
toma como caso la reforma procesal penal federal de la Argentina, y las dimensiones que permitieron dinamizar la transformación del "sistema inquisitivo"7 del enjuiciamiento penal local en pos de la instauración del "sistema acusatorio", además de su impacto en otros países de Latinoamérica. En este recorrido vale la pena destacar que el objeto empírico de la investigación se encontró en el activismo jurídico de los agentes que han luchado por conquistar la transformación del proceso penal federal en la Argentina. En el transcurso del trabajo de investigación se constató que los principales impulsores de la reforma han sido jueces, quienes por dicho motivo protagonizan estas páginas.

Para dimensionar la relevancia de la temática resulta preciso aclarar que el procedimiento procesal penal federal en la Argentina se aboca a regir las reglas del juzgamiento de delitos federales como: el terrorismo, los crímenes de lesa humanidad, la falsificación de moneda, la trata de personas, el narcotráfico y la corrupción. Por esta razón, los expertos del derecho que abrazan la causa de la reforma le confieren una significación sustantiva en materia criminal estatal, ya que la vinculan en sus discursos con "la persecución del gran delito", la "lucha contra las mafias" y la vigencia de los derechos humanos (Mira, 2017, 2020). En otras palabras, para los promotores de la reforma acusatoria la misma se asocia con el respeto a los valores republicanos y democráticos establecidos en la Constitución de la Nación Argentina. Este ideario, en el escenario democrático iniciado en el año 1983, incluye tanto el debate de la época en torno a la persecución penal de los grandes delitos vinculados a las masivas violaciones a los derechos humanos y la lucha contra la impunidad de la corrupción como la configuración y el cumplimiento insoslayable de las garantías procesales para quienes atraviesan un conflicto penal.

En la historia argentina se han dictado tres leyes de articulados en materia procesal penal federal (ver anexo 1). El primero fue el Código de

\footnotetext{
En cuanto a la controversia en torno a los "sistemas inquisitivo-acusatorio" se recomienda para su profundización tener en cuenta los trabajos de Máximo Langer (2007, 2014) en los cuales el autor, desde una perspectiva jurídica, se adentra en los sentidos, las conceptualizaciones, los usos y las implicancias que han tenido dichas categorías en la constitución de la disciplina del derecho procesal penal en el campo transnacional y en las políticas públicas. Langer (2014) llega a la siguiente conclusión: "para que el derecho procesal comparado expanda sus horizontes debe trascender las categorías acusatorioinquisitivo sin dejar de lado ni olvidar todo lo que estas categorías y su larga sombra nos han permitido ver y hacer" (p. 27).
} 
Procedimientos en lo Criminal, Ley N 2372 del año 1888, conocido como "Código Obarrio" en honor a su redactor Manuel Obarrio. El segundo fue el Código Procesal Penal de la Nación, Ley N² 23984 del año 1991, también llamado "Código Levene" en referencia a su redactor Ricardo Levene (h.) quien había realizado un proyecto anterior en esta misma materia en el año 1975, aunque cabe resaltar que por el golpe de Estado del año siguiente no fue posible el debate parlamentario sobre esta propuesta. Por último, el tercero es el Código Procesal Penal de la Nación, Ley N 27063 del año 2014, promulgado durante la última época de la presidencia de Cristina Fernández de Kirchner (alianza Frente para la Victoria, 20072015) a partir de un proyecto del propio poder ejecutivo nacional. Es relevante mencionar que fue suspendida la vigencia de este código por el decreto de necesidad y urgencia $N^{\circ} 257$ del año 2015 al inicio del mandato del presidente Mauricio Macri (alianza Cambiemos, 2015-2019). Con el correr de los años y luego de superar un complejo proceso de reforma, con la nueva denominación de Código Procesal Penal Federal finalmente comenzó a aplicarse el 10 de junio del año $2019^{8}$. Esta normativa se encuentra en la actualidad vigente en la Argentina, por un lado, en forma total en algunas jurisdicciones a partir del plan escalonado de implementación y, por otro lado, en forma parcial en todo el país por la aplicación de algunos artículos determinados sin restricción territorial.

A lo largo del desarrollo histórico de la reforma, Levene (h.) y Maier se destacan entre los expertos del derecho penal por ser pioneros, ya que fueron quienes bregaron por la transformación procesal penal federal que, con sus matices, ambos definieron como "acusatoria". Con sus propuestas de reforma promovieron reemplazar al "Código Obarrio" por ser considerado por sus detractores como inquisitivo, colonial, viejo y caduco. Los "reformadores" plantean con determinación y contundencia que la crisis del sistema procesal penal se debe a su "configuración inquisitorial". Los agentes entienden como "sistema inquisitivo" a la forma del procedimiento penal donde priman: el secreto y la escritura en el

La Ley $\mathrm{N}^{\circ} 27482$, del 6 de diciembre del año 2018, aprobó y modificó el texto del nuevo Código Procesal Penal de la Nación a la vez que sustituyó la denominación por la de Código Procesal Penal Federal y que determinó las medidas orientadas a la implementación progresiva de la normativa en los juzgados federales del país. El texto ordenado bajo la denominación de Código Procesal Penal Federal (T.O. 2019) se aprobó por el decreto 118/2019. Se encuentra disponible su articulado completo en el siguiente enlace: http://servicios.infoleg.gob.ar/infolegInternet/anexos/0-4999/383/texact.htm. 
desarrollo de los actos procesales, la figura del juez con funciones tanto acusatorias como decisorias en detrimento del rol del fiscal y la debilidad de la víctima que resulta expropiada del conflicto (Binder, 1993; Bovino, 1993; Córdoba, 1993; Levene, 1993; Maier, 1987, 1996).

En el presente artículo se propone reconstruir el proceso de reforma a partir de sus protagonistas y, se trata, en forma central sobre Levene (h.) y Maier quienes alcanzaron posiciones destacadas en el mundo del derecho, entre ellas, sus desempeños como jueces de máximos tribunales en la Argentina. Con este propósito, se presenta un apartado metodológico que aborda el trabajo sociológico con las trayectorias de los "reformadores" del derecho penal que ocupan lugares cumbre en la vida social en el ámbito de la justicia y la academia. Luego, se expone el análisis de las propiedades sociales y los vínculos internacionales que emanan de las trayectorias de Levene (h.) y Maier por ser los promotores de la reforma acusatoria del proceso penal a nivel federal en la Argentina. A continuación, se refiere a la circulación transnacional de estas figuras y a los fenómenos de importación/exportación del saber jurídico. Como asítambién se elabora en torno a las empresas del derecho comparado en materia procesal penal que protagonizaron los "reformadores". Por último, en las conclusiones se pone en valor la estrategia del trabajo con trayectorias que el caso de los "reformadores" argentinos las cuales demuestran su internacionalización, es decir su formación y trabajo en el exterior, hallazgo que resulta útil para pensar en la circulación de las ideas de reforma de la justicia penal y su impacto en el cambio de la legislación.

\section{Metodología y perspectiva teórica: Reconstrucción $\mathrm{y}$ análisis de trayectorias}

Esta investigación cualitativa se focalizó en reconstruir las trayectorias de los agentes promotores de la reforma procesal penal y su activismo por esta causa. El trabajo de campo se diseñó con una perspectiva etnográfica (Mira, 2019) ${ }^{9}$ centrada en seguir a los actores (Guber, 1991) en sus diversos espacios de actuación. Con este propósito y en particular para desarrollar la cuestión que aquí se aborda se recurrió a las frondo-

\footnotetext{
$9 \quad$ En este artículo se desarrolla la experiencia de construcción de una estrategia de investigación socio-jurídica, los desafíos encontrados en el campo y las formas de llevar adelante el trabajo con una perspectiva reflexiva.
} 
sas obras de los "reformadores", como sus textos, artículos y proyectos de ley, a la vez que a sus curriculum vitae $(\mathrm{CV})^{10} \mathrm{y}$ a sus legajos docentes de la Facultad de Derecho de la Universidad de Buenos Aires (UBA) que se encuentran en el museo de dicha institución.

En forma simultánea se recolectó información por medio de las entrevistas realizadas en profundidad, por la autora, a los propios protagonistas de la reforma procesal penal. Asimismo, se recuperaron entrevistas que fueron realizadas por terceros en diversos soportes. Se resalta que en el marco de la investigación fue posible entrevistar a los expertos del derecho, destacados por su vinculación con los proyectos de reforma procesal penal federal desde la reinstauración de la democracia, ellos son: Julio Maier, Alberto Binder y Carlos Beraldi. En el caso de Levene (h.), se entrevistó a su hijo Ricardo Levene nieto (n.). Este trabajo de campo fue factible en virtud de la construcción deliberada de vínculos personales en el terreno, los cuales han sido de dos tipos: algunos directos fruto de encuentros personales en múltiples eventos del mundo del derecho, o bien otros indirectos al ser mi pedido referido por otra persona de confianza perteneciente a dicho mundo y a quien previamente había logrado contactar. Esta última dinámica permitió establecer una cadena de vinculaciones en el campo, es decir, un proceso de incorporación de nuevos entrevistados que es comúnmente llamado efecto bola de nieve (Guber, 1991).

Para el análisis de las trayectorias biográficas y de las carreras activistas se adopta la perspectiva analítica desarrollada centralmente por Howard Becker (2010), Pierre Bourdieu (1998, 2011), Éric Agrikoliansky (2001), Olivier Fillieule (2001, 2010, 2015a, 2015b), y Luis Donatello y Federico Lorenc Valcarce (2016). La guía clave para este abordaje se encuentra en Bourdieu (2011), quien define a la trayectoria como la "serie de las posiciones sucesivamente ocupadas por un mismo agente (o un mismo grupo) en un espacio en sí mismo en movimiento y sometido a incesantes transformaciones" (p. 127). Otra conceptualización sumamente inspiradora se encuentra en Becker (2010), quien entiende la carrera en tanto a la sucesión de fases, cambios de los comportamientos y

10 El CV de Levene (h.) fue entregado en papel por su hijo durante la entrevista, en cambio el CV de Maier fue recuperado del sitio de la Facultad de Derecho de la UBA, el 17 de abril de 2009, de: http://www.derecho.uba.ar/multimedia/curriculum/cv_maier_01.pdf. 
de las perspectivas del individuo como al proceso que lleva a la conversión de un individuo en parte de un colectivo determinado.

También resultó ser una pauta analítica relevante de considerar el que Olivier Fillieule (2010) enumere los capitales que se adquieren por la socialización institucional, entre ellos los recursos entendidos como savoir-faire et savoir-être, una ideología, el ejercicio de una función de liderazgo formal o informal (pp. 91-92). Fillieule (2010) agrega que esta fuerza simbólica de la socialización amalgama las identidades individuales y colectivas, generando mecanismos de cohesión y vinculación emocional que refuerza la noción de pertenencia con un sentido de unión (p. 92). En otras palabras, estas dinámicas configuran los grupos que han entablado la competencia por la reforma de la justicia penal.

La interpretación de las trayectorias se concreta siguiendo las perspectivas teóricas mencionadas y, en particular, haciendo lugar a ciertas advertencias metodológicas esgrimidas por Bourdieu en relación con el abordaje de las historias de vida y las carreras. Por un lado, Bourdieu (2011) refiere a la ilusión biográfica como un relato narrativo coherente, con una proyección lineal y dotada de sentido intrínseco, por otro lado, alerta sobre el "obstáculo al conocimiento científico del mundo social" (p. 127) generado en la "ilusión de lo natural y la ilusión de que 'siempre ha sido asi'”' (p. 127). Con el fin de reconstruir los recorridos personales y profesionales también es productivo recurrir al concepto de habitus que "es sentido práctico (sentido del juego social) y tiene una lógica propia, que es necesario aprehender para explicar y comprender las prácticas" (Gutiérrez, 2010, p. 16). Gracias a esta referencia al habitus resulta posible "recordar la historicidad del agente" (Gutiérrez, 2010, p. 16), donde "lo individual, lo subjetivo, lo personal es social, es producto de la misma historia colectiva que se deposita en los cuerpos y las cosas" (Gutiérrez, 2010, p. 16). Para atender a estas premisas se incorporan tanto la dimensión histórica como la dimensión relacional en la reconstrucción de las trayectorias de los "reformadores" destacados de la justicia penal que ha tenido la Argentina, las cuales se presentan a continuación.

\section{Jueces, juristas y "reformadores" de la justicia penal: Ricardo Levene y Julio Maier}

El análisis de las trayectorias profesionales de los jueces Levene (h.) y Maier, en el contexto de las coyunturas históricas en las que fueron con- 
vocados para impulsar la reforma procesal penal en la justicia federal permite mostrar las propiedades sociales de los "reformadores" y sus lógicas de intervención en el campo jurídico. Al mismo tiempo, se presenta un análisis comparado de sus trayectorias con el propósito de destacar tanto recurrencias y elementos comunes como elementos heterodoxos solo identificables a partir de un análisis sociológico de los datos ofrecidos por sus biografías personales y profesionales (ver cuadro A). Este abordaje de la socialización de Levene (h.) y Maier da lugar a percibir notorias similitudes en los recorridos profesionales de ambas personalidades del mundo jurídico, quienes provienen de familias vinculadas al derecho, han concurrido a establecimientos educativos de elite y, en virtud, de su desempeño profesional notorio en relación con la reforma de la justicia han logrado gran reconocimiento nacional e internacional.

Vale aclarar que en la investigación se indagaron diversos capitales que explican sociológicamente el posicionamiento de Levene (h.) y de Maier en el campo del derecho y la justicia, desde su capital simbólico, a sus capitales sociales, familiares y económicos (Bourdieu, 1991, 1996, 1998; Dezalay \& Garth, 1998, 2003; Madsen, 2006). En este artículo, se centra la mirada en el capital simbólico en tanto fuente de legitimación para los expertos del derecho para el despliegue de sus acciones en el campo de la justicia. Para poder observar esta dimensión, sabemos que el capital simbólico resulta ofrecido centralmente por las credenciales y los vínculos académicos, incluyendo en este caso a los vínculos internacionales de los que se destacan los intercambios con Alemania. En este punto, se evidencia la circulación de agentes y capitales que, desde una perspectiva sociológica, se traduce en términos de un fenómeno de importación/exportación de los expertos y del saber en el campo de la reforma procesal penal (Dezalay \& Garth, 1998, 2003; Madsen, 2004, 2006). Otra perspectiva teórica complementaria consiste en la novedosa tradición promovida por la historia jurídica mundial (Duve, 2016), en la que se plantea la relevancia e incluso necesidad del estudio de la historia del derecho en forma global por medio de la cual podríamos enmarcar estos diálogos globales y las transformaciones legales locales.

Resulta ampliamente significativo tener presente que tanto Levene (h.) como Maier, aun perteneciendo a diversas generaciones de juristas, invirtieron gran parte de su carrera profesional a la crítica del "Código Obarrio”, vigente en la República Argentina entre los años 1888 y 1992, 
lo cual les hizo ganar el lugar de "padres de la reforma". Ambos "reformadores" adoptaron su postura al considerar la "tradición inquisitiva" del Código de Procedimientos en lo Criminal de 1888 vinculada con su origen en el derecho español y a su falta de modernidad. Realizaron su trabajo de crítica de un modo muy laborioso, ya que le dedicaron a esta causa diversas tareas: desde el estudio de los códigos procesales penales de otros países, la escritura de manuales en la materia, la participación en congresos profesionales y en encuentros académicos tanto en el país como en el exterior, hasta la elaboración de proyectos de códigos procesales penales alternativos, tanto para la justicia federal como para la justicia provincial e incluso participando en procesos de reforma de la justicia penal fuera de la Argentina. Todas estas acciones, sostenidas en el tiempo, construyen una razón reformadora, en tanto la dinámica de presentación de críticas a la norma vigente y la generación de alternativas por medio de un cambio de la legislación (Vauchez \& Willemez, 2007).

A pesar de estos elementos comunes, la competencia que entablaron Levene (h.) y Maier en torno a la paternidad del nuevo código en materia procesal penal para la justicia federal que se proponía reemplazar al Código de 1888 los llevó a cruzar duras críticas entre ellos, trascendiendo la crítica compartida a Obarrio. Levene (h.) expuso las debilidades del "Proyecto Maier" cuando se estaba debatiendo en el Congreso de la Nación luego de haber sido presentado por el poder ejecutivo. Por su parte, Maier coordinó un seminario de investigación en la Facultad de Derecho de la Universidad de Buenos Aires (UBA) para analizar en forma crítica al "Código Levene", producto del cual se publicó el libro titulado: $E l$ nuevo Código Procesal Penal de la Nación. Análisis crítico, Editores del Puerto (Maier, 1993b). Ambos juristas reivindican en su labor de codificación el uso de antecedentes de importancia tanto del derecho de otros países como del derecho argentino. Las armas en este combate son las herramientas técnicas que proveen el derecho y la ocupación de múltiples espacios en el ámbito profesional.

Como se adelantó, Levene (h.) finalmente logró que, transcurrida más de una centuria de vigencia del "Código Obarrio", su proyecto de reforma se transforme -con algunas modificaciones relevantes que se introdujeron en el debate parlamentario- en el nuevo Código Procesal Penal de la Nación en el año 1991, el cual instauró la oralidad en los juicios únicamente en la etapa de debate. Esto sucedió, no casualmente, 
cuando Levene (h.) ocupaba el cargo de presidente de la Corte Suprema de Justicia de la Nación en momentos en que Carlos Saúl Menem se desempeñaba como Presidente de la República Argentina, a quien esta reforma le permitió promover transformaciones notorias en el funcionamiento de la justicia federal, creando juzgados y nombrando jueces. Es un dato relevante tener presente que Levene (h.) recuperó el 23 de abril de 1990 la posición de ministro en la Corte Suprema y dos días más tarde sería propuesto como su presidente. Este cargo lo había ocupado por primera vez en el año 1975 y lo había perdido a causa del golpe militar del 24 de marzo de 1976. Levene (h.) regresó a su posición en la Corte Suprema luego de transitar toda su vida en el poder judicial ${ }^{11}$.

Esta reforma exitosa, fundada en el articulado propuesto por Levene (h.) como presidente del principal tribunal del país y promovida desde el gobierno, desplazó al "Proyecto Maier" del año 1986. Sin embargo, este hecho no ha menoscabado la enorme influencia sin fronteras del trabajo intelectual de $\mathrm{Maier}^{12}$. La historia muestra que la contienda aparentemente concluida con la promulgación de la Ley $\mathrm{N}^{\circ} 23984$ en 1991 se mantuvo viva dando lugar a la continuidad del proyecto reformador acusatorio. La disputa continuó fundada en que el "Código Levene" fue acusado muy tempranamente de ser "mixto" e "inquisitivo reformado", es decir, no plenamente acusatorio ni oral. En otras palabras, esta reforma mantenía un momento denominado "inquisitivo" en la primera etapa del proceso por medio de una investigación escrita en un expediente y dirigida por un juez, a menos que este decidiera voluntariamente delegarla a un fiscal. A partir de estos diagnósticos que cimentaron una razón reformadora, se generaron

11 Levene (h.), al llegar a la máxima posición como juez, con anterioridad había ocupado cada uno de los diferentes peldaños de la estructura jerárquica, iniciada desde la posición más baja conocida con la denominación de "meritorio" (un joven que realiza las tareas más básicas de asistencia sin paga alguna).

12 Ya que fue el experto quien redactó el Código Procesal Penal Modelo para Iberoamérica por encargo del Instituto Iberoamericano de Derecho Procesal. Maier se convertiría en el primer presidente del nuevo Tribunal Superior de Justicia de la Ciudad Autónoma de Buenos Aires, del que fue juez entre los años 1998 y 2009, gracias a sus antecedentes y meritoria carrera de décadas que incluían su labor como jurista y codificador. Durante sus últimos años como juez en dicho Tribunal también mantuvo su vocación reformadora. El Proyecto de Código Procesal Penal para la Ciudad Autónoma de Buenos Aires fue el último intento reformador de Maier, el cual tampoco logró convertirse en ley (en base a otro proyecto este Código fue promulgado en el año 2007). Se retoman estas cuestiones en el apartado 3.2 de este texto. 
una variedad de propuestas de reforma que se filiaron a la iniciativa previa de Maier y mantuvieron la disputa abierta por varias décadas.

En consecuencia, la causa reformadora se convierte en el signo distintivo que connota a las múltiples acciones colectivas que los expertos del derecho promueven con el propósito de transformar la legislación vigente en materia procesal penal y, en particular, Maier y Alberto Binder -su colaborador que más tarde ganaría autonomía- con el fin trascendente de "humanizar" y "democratizar la justicia" (Binder, 1993; Maier, 1993a). La meta de la humanización sus impulsores afirman que se lograría fundamentalmente por medio de la oralidad en el juicio que ponga en diálogo en la escena tribunalicia a las partes del proceso penal, es decir, los actores de la justicia, los acusados y las víctimas (Mira, 2017, 2020). Desde la perspectiva de los "reformadores" la democratización, por un lado, se gestaría con la publicidad del proceso penal y, por otro, se conquistaría centrando el foco del tratamiendo penal en los crímenes federales más relevantes para la sociedad -como la corrupción y los crímenes que atentan contra los derechos humanos- a partir de la función vigorizada de la fiscalía en la selección de los casos y su investigación (Mira, 2017, 2020).

Este recorrido propuesto a través de las trayectorias de Levene (h.) y Maier, facilita mostrar la forma en que quienes se presentan en torno a una contienda como figuras antitéticas dentro del campo, como son los casos de Levene (h.) y Maier, se caracterizan por compartir un sinnúmero de propiedades sociales. Estas características compartidas se despliegan en el campo profesional de forma multisituada en los roles de codificadores, profesores y jueces. En otras palabras, se evidencia que ambos "reformadores" más allá de su diferencia generacional coincidieron en los términos de su lucha contra su antecesor Obarrio, lo cual se explica por la larga vigencia del primer código en materia procesal penal. No obstante, Levene (h.) y Maier rápidamente se posicionaron en grupos opuestos y contrincantes por ganar la batalla por instaurar el código que reemplace al denominado "sistema inquisitivo". En este contexto, las categorías "inquisitivo" y "acusatorio" trascienden los criterios técnicos jurídicos y se establecen como marcos de referencia e identificación de los grupos de juristas penalistas en pugna, quienes logran una fuente de legitimación decisiva por sus roles desempañados dentro del poder judicial. Es decir, no resultaría 
posible explicar su rivalidad únicamente en términos de diferencias teóricas o conceptuales en materia de derecho procesal penal sino que su competencia obedece a improntas políticas y a una disputa de poder en el propio campo del derecho para ser quienes dicen el derecho.

El trabajo de campo evidenció que los grupos comprometidos con la reforma se nuclean alrededor de figuras destacadas, como lo fueron indiscutiblemente Levene (h.) y Maier, estableciendo de algún modo linajes que, con el paso del tiempo, incluso se ven atravesados por disputas y rupturas. La atribución del nombre de un jurista al proyecto o código muestra cómo la comunidad de pares reconoce a las figuras prototípicas que impulsan los proyectos, caracterizadas siempre por un alto capital simbólico dentro del campo. Mediante esta forma de nominación de los códigos se honra a los juristas que impulsan la iniciativa, pasando a ser reconocidos los textos mediante los nombres propios de quienes los gestaron con independencia de los números de leyes correspondientes -por este motivo se habla del "Código Obarrio" y del “Código Levene”. Lo mismo sucede con los proyectos de reforma que no lograron convertirse en leyes (ver anexo 2), como el caso del emblemático "Proyecto Maier" (1986) y de iniciativas posteriores conocidas como el "Proyecto Beraldi" (2007) y el “Proyecto Albrieu” (2010).

Levene (h.) y Maier, los llamados "padres de la reforma" del Código de Procedimientos en lo Criminal para la justicia nacional contaron con prominentes características en común: desarrollaron una extensa trayectoria en la justicia llegando a ocupar posiciones destacadas en máximos tribunales del país; se desempeñaron como docentes titulares en materias de derecho penal en la universidad hasta convertirse en profesores eméritos; escribieron manuales y tratados de derecho procesal penal; crearon instituciones de derecho penal comparado; mantuvieron vínculos con Europa, en particular con Alemania; tuvieron membresías en instituciones relevantes en todo el mundo; recibieron homenajes, honores y distinciones por su contribución al derecho; y desarrollaron labores de relevancia a nivel internacional (ver cuadro A). Así también pueden identificarse los idearios y las cosmovisiones compartidos por ambos en relación con el derecho penal y a la función de la justicia, entre ellos: la limitación al poder punitivo del Estado, la aspiración a la oralidad y el respeto a las garantías de los imputados (Mira, 2017, 2020). 
Este fenómeno de internacionalización promueve advertir el peso específico que gana en la construcción de estos agentes centrales en la transformación del modelo de Estado en materia de impartición de justicia penal. A continuación se despliega, en primer lugar, la circulación transnacional personal de Levene (h.) y Maier en torno a la configuración de sus trayectorias personales y académicas con su consecuente impacto en la importación/exportación de conocimiento jurídico en materia de derecho procesal penal, lo cual advierte que logró una relevante influencia que trasciende la Argentina y alcanza la región latinoamericana. En segundo lugar, se presentan los roles de estas figuras destacadas como hacedores del derecho profundamente inspirados e influenciados por el derecho penal comparado desde un enfoque institucional. Se aclara que se trata de dos dimensiones extrechamente vinculadas que se distinguen a título meramente analítico para facilitar la presentación de la temática y que pueden, por ese motivo, tanto superponerse como solaparse.

Cuadro 1

Comparación de las trayectorias de los jueces "reformadores" del procedimiento procesal penal federal en la Argentina durante el siglo XX

\begin{tabular}{|c|c|c|}
\hline $\begin{array}{l}\text { Dimensión / } \\
\text { Jurista }\end{array}$ & $\begin{array}{l}\text { Levene (h.), Ricardo } \\
\text { (1914-2000) }\end{array}$ & $\begin{array}{l}\text { Maier, Julio } \\
\text { (1939) }\end{array}$ \\
\hline Familia & $\begin{array}{l}\text {-Padre abogado, historiador } \\
\text { del derecho. }\end{array}$ & -Padre abogado. \\
\hline Formación & $\begin{array}{l}\text {-Colegio Nacional de Buenos } \\
\text { Aires (CNBA). } \\
\text {-Abogado y escribano, } \\
\text { Universidad de Buenos Aires } \\
\text { (UBA). }\end{array}$ & $\begin{array}{l}\text {-Liceo Militar Córdoba. } \\
\text {-Abogado, Universidad } \\
\text { Nacional de Córdoba (UNC). }\end{array}$ \\
\hline $\begin{array}{l}\text { Estudios de } \\
\text { posgrado }\end{array}$ & -Doctorado, UBA. & $\begin{array}{l}\text {-Formación de posgrado } \\
\text { en Alemania, becario de la } \\
\text { Deutscher Akademischer } \\
\text { Austausch Dienst -Servicio } \\
\text { Alemán de Intercambio } \\
\text { Académico- (DAAD). } \\
\text {-Doctorado, UNC, } 1972 . \\
\end{array}$ \\
\hline $\begin{array}{l}\text { Vinculaciones } \\
\text { con instituciones } \\
\text { (destacadas) }\end{array}$ & $\begin{array}{l}\text {-Instituto de Derecho Penal- } \\
\text { Comparado, Universidad } \\
\text { Católica de La Plata (UCLP), } \\
\text { fundador. } \\
\text {-Centro de Estudios de } \\
\text { Derecho Procesal Penal, } \\
\text { fundador. } \\
\text {-Organización de las Naciones } \\
\text { Unidas (ONU), experto. }\end{array}$ & $\begin{array}{l}\text { - Instituto de Derecho Procesal } \\
\text { Latinoamericano. } \\
\text {-Instituto de Estudios } \\
\text { Comparados en Ciencias } \\
\text { Penales y Sociales (INECIP), } \\
\text { fundador. } \\
\text {-ONU. }\end{array}$ \\
\hline
\end{tabular}




\begin{tabular}{|c|c|c|}
\hline $\begin{array}{l}\text { Vinculaciones } \\
\text { trasnacionales } \\
\text { (principales) }\end{array}$ & $\begin{array}{l}\text {-Alemania. } \\
\text {-Estados Unidos. } \\
\text {-Costa Rica. }\end{array}$ & $\begin{array}{l}\text {-Alemania. } \\
\text {-Centro América. } \\
\text {-América Latina. }\end{array}$ \\
\hline $\begin{array}{l}\text { Poder Judicial } \\
\text { (máxima posición } \\
\text { alcanzada) }\end{array}$ & $\begin{array}{l}\text {-Ministro de la Corte Suprema } \\
\text { de Justicia de la Nación (CSJN), } \\
\text { en los períodos 1973-1976 y } \\
\text { 1990-1995. }\end{array}$ & $\begin{array}{l}\text {-Juez del Tribunal Superior } \\
\text { de Justicia (TSJ) de la Ciudad } \\
\text { Autónoma de Buenos Aires, en } \\
\text { el período 1998-2009. }\end{array}$ \\
\hline $\begin{array}{l}\text { Vida académica } \\
\text { (máximas } \\
\text { posiciones } \\
\text { alcanzadas) }\end{array}$ & $\begin{array}{l}\text {-Decano. } \\
\text {-Profesor emérito. } \\
\text {-Director del Instituto de } \\
\text { Derecho Penal, UBA. } \\
\text {-Director del Centro de } \\
\text { Criminalística, UBA. } \\
\text {-Director del Instituto de } \\
\text { Derecho Procesal, Universidad } \\
\text { Nacional de La Plata (UNLP). } \\
\text {-Director Doctorado Ciencias } \\
\text { Jurídicas - Derecho Penal, } \\
\text { Universidad del Salvador } \\
\text { (USAL). }\end{array}$ & $\begin{array}{l}\text {-Profesor emérito. } \\
\text {-Director del Departamento de } \\
\text { Derecho Penal y Criminología, } \\
\text { UBA. } \\
\text {-Director Departamento de } \\
\text { Graduados, UBA. }\end{array}$ \\
\hline $\begin{array}{l}\text { Ejercicio } \\
\text { profesional } \\
\text { privado }\end{array}$ & $\begin{array}{l}-1955 . \\
-1976 .\end{array}$ & $\begin{array}{l}\text {-1982-1998: } \\
\text { Estudio Galante } \\
\text { Estudio Maier, Pastor \& Salt. }\end{array}$ \\
\hline $\begin{array}{l}\text { Reconocimientos, } \\
\text { premios y } \\
\text { distinciones } \\
\text { (principales) }\end{array}$ & $\begin{array}{l}\text {-Beca Fulbright, Estados } \\
\text { Unidos de Norteamérica, } 1978 . \\
\text {-Libro de oro de la Asociación } \\
\text { de Rectores y Rectoras de } \\
\text { la República Argentina } \\
\text { (AREPRA), } 1990 . \\
\text {-Medalla de Oro como ex } \\
\text { alumno más destacado del } \\
\text { CNBA, 1991. } \\
\text {-Primer Premio } \\
\text { Latinoamericano al Mérito } \\
\text { Jurídico en Decanato, } 1994 . \\
\text {-Homenaje a } 15 \text { años de su } \\
\text { fallecimiento, } 2015 .\end{array}$ & $\begin{array}{l}\text {-Beca DAAD, Alemania, } 1963 . \\
\text {-Beca Humboldt, Alemania } \\
1976 . \\
\text {-Doctor Honoris Causa, } \\
\text { Universidad Nacional } \\
\text { deTrujillo, 2006. } \\
\text {-Libro homenaje, } 2005 . \\
\text {-Celebración de su 70 } \\
\text { cumpleaños, UBA. } \\
\text {-Libro homenaje, } 2010 . \\
\text {-Premio Konex, 2006. } \\
\text {-Premio Montesinos, } 2007 .\end{array}$ \\
\hline
\end{tabular}

Fuente: Elaboración propia en base a CV, libros, entrevistas, sitios institucionales y a las múltiples fuentes de mi investigación (Mira, 2017). Se aclara que dada la prolífera vida de ambos juristas y jueces esta síntesis no tiene una pretensión de exhaustividad.

\subsection{Circulación internacional: Importación y exportación del saber jurídico}

Como se mencionó en las páginas anteriores, la dimensión trasnacional fue intensamente cultivada por Levene (h.) y Maier gracias a múltiples formatos y por medio del multiposicionamiento en diversos espacios sociales, como el mundo académico y el mundo de la 
justicia. En este recorrido ambos referentes mantuvieron estrechos vínculos con Europa en particular con Alemania, a la vez que fueron convocados para colaborar con reformas de la justicia en América Latina y América Central, lo cual dio lugar a su amplia circulación internacional. Al mismo tiempo, gestaron vinculaciones con universidades del mundo y organismos internacionales, lograron numerosas membresías y distinciones en prestigiosas instituciones con relevancia a nivel mundial.

El autor del "Código Levene" también desarrolló fuertemente su profesión fuera de la Argentina, a modo de jurista experto, profesor y académico. Su intensa vinculación internacional fue tanto con los Estados Unidos de Norteamérica como con Europa y Latinoamérica. En forma destacada estrechó relaciones con la Organización de las Naciones Unidas (ONU), institución que lo convocó a participar como experto en iniciativas vinculadas a la justicia y a la legislación en los años: 1975, 1980, 1981 y 1984. En 1980 resulta nuevamente invitado por la ONU a Costa Rica "para asesorar a la Corte Suprema y el Ministerio de Justicia” (CV Levene). Un año más tarde, en 1981, fue convocado por la ONU "para integrar un panel de expertos y tratar el tema de los 'Problemas de la justicia en la legislación comparada'" que tuvo lugar en Buenos Aires (CV Levene).

Levene (h.) realizó varios viajes a la República Federal Alemana como invitado del gobierno alemán o de la Embajada de Alemania en la Argentina cuando ya era reconocido por su pericia jurídica, en los años: 1970, 1971, 1976 y 1977. En estos viajes tuvo la oportunidad de "recorrer sus centros universitarios y criminológicos, sus establecimientos carcelarios, dar conferencias y efectuar tareas de investigación" (CV Levene). En particular, en 1971, fue invitado por el MaxPlanck-Institut für ausländisches und internationales Strafrecht -el Instituto Max-Planck para el Derecho Penal Extranjero y el Derecho Penal Internacional- de Freiburg, dirigido por el profesor Hans-Heinrich Jescheck, para dictar clases durante un semestre sobre criminología y derecho penal comparado. El 2 de julio de ese mismo año, en Freiburg, Levene (h.) brindó una conferencia sobre el problema de la reforma procesal penal argentina, titulada Reformprobleme des argentinischen Strafprozenßrechts, organizada nuevamente por el Max-Planck-Institut y la Rechtswissenchaftliche Fakultät (CV Levene). La importancia de es- 
tos vínculos con el derecho alemán se pone de manifiesto con fuerza cuando Levene (h.) es invitado como experto en derecho penal comparado para formar parte de la Comisión de Reforma del código penal de la República Federal Alemana (1973-1975).

El mundo asociativo también fue notoriamente habitado por Levene (h.), quien formó parte de diversas asociaciones profesionales mundiales en su especialidad y recibió distinciones de sus pares en distintas partes del mundo. A modo de ejemplo, este jurista fue miembro de la International Association of Criminology y de la International Association of Criminal Law (CV Levene resumido en inglés), y designado miembro de honor del Instituto Peruano de Derecho Procesal. En este marco, recibió múltiples reconocimientos de sus pares, entre otros obtuvo el primer premio latinoamericano al Mérito Jurídico en Decanato, otorgado por la Confederación Latinoamericana de Colegios y Asociaciones de Abogados, de México (1994) (CV Levene).

$\mathrm{Al}$ analizar el caso de los vínculos de Maier con juristas en el exterior se observa que se gestan fundamentalmente en su época de estudiante de posgrado en Alemania. Maier se trasladó a la Universidad de Múnich para realizar sus estudios en filosofía jurídica, derecho penal y derecho procesal penal gracias a una beca de la Deutscher Akademischer Austausch Dienst -Servicio Alemán de Intercambio Académico(DAAD) para el período 1963-1965, al poco tiempo de haberse graduado como abogado en la Universidad Nacional de Córdoba (UNC) en 1963, lo cual evidencia una oportunidad de acceso a credenciales internacionales (Dezalay \& Garth, 1998, 2003). También en la UNC Maier obtuvo su Doctorado en Derecho y Ciencias Sociales en 1972, tras concluir su primera estadía en Alemania, con una disertación sobre el derecho procesal alemán que pocos años más tarde se publicó en el libro: La Ordenanza Procesal Penal Alemana. Su comentario y comparación con los sistemas de enjuiciamiento penal argentinos (1978).

La segunda estadía de Maier en el exterior fue en el período 19761978 en forma coincidente con el último golpe de Estado en la Argentina y luego de sufrir un atentado con una bomba que destruyó parte de su vivienda dada su función en la justicia (Córdoba, 2010; Goransky, 2005; Entrevista, 2012). En dicha oportunidad, fue becario de la fundación Alexander von Humboldt en la República Federal de Alemania y se desempeñó como investigador en el Seminario de Filosofía Jurídica 
de la Universidad de Bonn con el afamado profesor Armin Kaufmann. Maier realizó su última instancia de investigación en Alemania al momento de cumplir los 70 años de edad, nuevamente bajo el auspicio de la Fundación Humboldt (Córdoba, 2010).

La tesis doctoral de Maier es considerada por su discípulo Daniel Pastor (2009) en los términos de "una exposición sistemática del Derecho procesal penal alemán acompañada de una traducción insuperable de la StPO" (p. 162) -la sigla se refiere a la Strafprozeßordnung que puede traducirse como la Ordenanza Procesal Penal alemana con equivalencia práctica a un código de procedimientos en materia penal. Este trabajo de traducción a partir de la primera estadía de Maier en Alemania dio lugar a que "el mundo hispanohablante comienza a conocer y a prestar atención también al Derecho procesal penal alemán y a los autores alemanes difundidos por este notable jurista" (Pastor, 2009, p. 162). Pastor (2009) da cuenta de la novedad que aporta su maestro en su Proyecto de Código Procesal Penal para la Nación con la introducción del rol decisivo del fiscal en la etapa de investigación, originada en la "abolición a la alemana de la instrucción judicial" (p. 162) con el desplazamiento del juez instructor en su rol de investigación de los hechos, ya que continua afirmando el autor:

La labor de Maier tuvo una repercusión decisiva que trascendió el lucimiento teórico de quien domina las técnicas del Derecho comparado, pues el modelo alemán estudiado por Maier y confrontado con los sistemas argentinos aportaba una novedad llamativa: la reforma alemana en vigor desde 1975 había logrado insertar exitosamente en un modelo de Derecho procesal penal codificando el señorio de la fiscalía en la etapa de investigación [las cursivas me pertenecen] La necesidad de una "abolición" a la alemana de la instrucción judicial, propuesta por Maier también para nosotros, iba a presidir, a partir de sus trabajos de difusión de la teoría y de la legislación procesal alemana, la discusión de la reforma en Iberoamérica durante treinta años. (Pastor, 2009, p. 162).

La inscripción de Maier en la academia germana en el momento de la reforma de 1975 le permitió el desarrollo de su original y pionero tema de tesis doctoral que lo convirtió en el primer traductor al español de la Orden Procesal alemana. Esta labor de traducción se convierte en una herramienta clave para la importación del derecho procesal ale- 
mán en el continente latinoamericano, el que se encontraba notoriamente influido por el derecho español (y de allí se origina la acusación al derecho local de "colonial"). Esta labor reforzó su reconocimiento como experto en la materia e impulsó su trabajo en el continente latinoamericano promoviendo diversas reformas de normativas penales. Estas gestas por la transformación legislativa significaban también para sus impulsores una forma robusta para trascender la herencia normativa española.

Maier, por estos motivos fuertemente arraigados a su historia biográfica, será quién protagonizará la introducción vigorosa del pensamiento procesal penal germano en la Argentina en virtud del tiempo que transcurrió en Alemania, como doctorando en la Universidad de Múnich y sus posteriores múltiples vinculaciones con la academia alemana. A partir de la década del sesenta del siglo XX, el jurista comienza a difundir tanto a autores alemanes como a las reformas procesales allí realizadas en base a su conocimiento personal de los mismos y al trabajo de traducción que ha realizado del alemán al español tanto de la legislación alemana como de autores alemanes. La vinculación de Maier con el exterior incluye ser asesor de diversas publicaciones, entre las que se destaca la Zeitschrift für die gesamte Strafrechtswissenschaf, la cual "se publica ininterrumpidamente desde su fundación en 1881 por Adolft Dochow y Franz von Liszt, uno de los creadores de la ciencia moderna del derecho penal" (Córdoba, 2010, p. 15).

Al contemplar la trayectoria de Maier, resulta sumamente significativo apreciar la esmerada forma con que él conserva y alimenta apasionadamente su vínculo con sus pares germanos durante toda su vida. Al mismo tiempo, Maier le confiere a esta tradición de conocimiento un valor de gran envergadura, por lo cual busca que los vínculos con Alemania lo trasciendan al promover con plena convicción que sus discípulos argentinos estudien la lengua alemana y se formen en universidades alemanas. En esta línea, varios discípulos de Maier, gracias a su estímulo y apoyo, logran doctorarse como así también desarrollan períodos de formación de posgrado en Alemania para más tarde continuar los vínculos académicos con profesores alemanes. Al igual que su maestro, los discípulos más cercanos de Maier, y quienes se doctoraron bajo su dirección, luego contaron con una beca postdoctoral de la Fundación Alexander von Humboldt. Se trata de los destacados juristas y 
actuales profesores de derecho penal en la Universidad de Buenos Aires (UBA): Daniel Pastor, Marcelo Sancinetti, Eugenio Sarrabayrouse y Patricia Ziffer (Córdoba, 2010; Entrevista, 2012). Recuerda Gabriela Córdoba (2010) que Maier:

ha impulsado a gran cantidad de discípulos a profundizar su educación jurídica en el extranjero, para lo cual el patrocinio de Maier fue determinante para que las universidades del exterior les abrieran generosamente las puertas y las instituciones científicas de cooperación internacional les brindaran becas de investigación. (p. 17).

A lo largo de los años se fueron tejiendo y consolidando las redes académicas entre Argentina y Alemania, con intercambios de estudiantes y profesores en ambas direcciones. Un testimonio de las fecundas vinculaciones de Maier con Alemania se evidenció en la presencia notoria de los profesores germanos en el voluminoso libro homenaje que le dedicaron, titulado Estudios sobre Justicia Penal. Homenaje al profesor Julio B. J. Maier (2005). En el libro participan lo ssiguientes profesores alemanes: Winfried Hassemer, Albin Eser, Claus Roxin, Eberhard Struensee, Hans Joachim Hirsch, Friederick Dencker, Christian Jäger y Walter Perron.

Resulta singularmente ilustrativo el caso de Jan Woischnik, un joven alemán que realizó su investigación doctoral sobre la reforma del procesal penal federal en la Argentina, bajo la dirección del Prof. Walter Perron la cual fue defendida en la Johannes Gutenberg- Universität Mainz (Alemania). La tesis de Woischnik se publicó en el libro intitulado: Untersuchungsrichter und Beschuldigtenrechte in Argentinien: eine kritische Würdigung des neuen Bundesstrafverfahrensrechts anhand der rechtstaatlichen Vorgaben der Menschenrechtskonventionen (2001) ${ }^{13}$. Este trabajo de Woischnik pocos años más tarde se materializó en un libro en español y fue publicado gracias al apoyo de la fundación Konrad Adenauer Stiftung con el título: Juez de instrucción y derechos humanos en Argentina. Un análisis crítico del Código Procesal Penal de la Nación (2003). Merece la pena detenerse en este libro de Woischnik (2003) ya que ejemplifica los múltiples intercambios institucionales y

13 Puede traducirse en español como: Juez instructor y los derechos de los acusados en la Argentina: Un análisis crítico del nuevo derecho procesal penal federal a través de las normas de las convenciones de los Derechos Humanos. 
personales entre Alemania y la Argentina. En esta producción académica se muestra la fuerza de las relaciones entre generaciones al interior de un mismo linaje, la diversidad de redes y de las actividades que los vinculan a todos como parte del grupo identificado con Maier.

Relata Maier (2003) en el prólogo del libro en español de Woischnik que un joven alemán había llegado a la Argentina para investigar y que él lo orientó para que conociera las prácticas judiciales desde dentro, gracias a sus amigos que en aquella época trabajaban en los tribunales penales o en el Ministerio Público de la Ciudad Autónoma de Buenos Aires. Maier (2003) muestra su satisfacción al comprobar que los vínculos académicos generados entre países separados por miles de kilómetros como Alemania y la Argentina: “...prosiguen entre los más jóvenes [las cursivas me pertenencen] y no solo a través de declamaciones o visitas, sino, antes bien, a través de obras concretas" ( $\mathrm{p}$. 20). Maier (2003) agrega que el propósito del joven estudiante le parecía propio de "turismo aventura" (p. 20), una empresa similar -pero con el destino inverso- a la que emprendió él mismo cuando viajó a Alemania por primera vez. Maier (2003) manifiesta que su proceso de formación intelectual depende de sus años de estudio en Alemania y su conocimiento del derecho alemán mientras que, por el contrario, la obra que prologa resulta valiosa para: "el conocimiento del Derecho procesal penal argentino, sino también para comprender y valorar décadas reformistas del Derecho procesal penal en Hispanoamérica que nos tocó vivir al final del siglo pasado" (p. 21).

Esta relación académica trascendió lo que parecía ser una anécdota ya que años más tarde Maier coordinaría junto a Woischnik y el profesor Kai Ambos ${ }^{14}$, la obra titulada: Las Reformas Procesales Penales en América Latina, publicada en el año 2000 por Ad-Hoc (con el apoyo del Max-Planck Institut für ausländisches und internationales Strafrecht y la Konrad Adenauer Stiftung). Para continuar estos múltiples vínculos entre la Argentina y Alemania en torno a la reforma derecho penal construidos a lo largo del tiempo y con diversos apoyos institucionales, menciono a modo de ejemplo, que Daniel Pastor, uno de los discí-

Ambos por aquel entonces se desempeñaba como director del Instituto Internacional de Ciencias Penales y Criminales de la Facultad de Derecho de la Georg-AugustUniversität Göttingen. 
pulos de Maier con quien fundó el Instituto de Estudios Comparados en Ciencias Penales y Sociales (INECIP), compartió la tarea docente y también laboral en un estudio jurídico, presentó la ponencia titulada El futuro de la reforma procesal penal en la Argentina y el aporte de la experiencia alemana, en el simposio argentino-alemán celebrado en diciembre de 2007 para conmemorar el $150^{\circ}$ aniverstario de las relaciones bilaterales entre la Argentina y Alemania y a partir del cual se publicó el libro Criminalidad, evolución del derecho penal y crítica al derecho penal en la actualidad (2009). Maier también promovió nuevas iniciativas de traducción de obras de autores alemanes, entre otras, el libro de Claus Roxin, Derecho Procesal Penal, traducido por Gabriela Córdoba y Daniel Pastor, "bajo su atento control” (Pastor, 2009, p. 163). Afirma Pastor (2009) que "se trata de un trabajo en común que empieza con la labor de Maier ya citada de exponer, explicar y traducir el Derecho procesal penal alemán" (p. 162).

Otro ejemplo de los intercambios de ideas jurídicas se encuentra cuando Maier había sido convocado por el "Centro para los Derechos del Hombre de las Naciones Unidas para analizar el sistema penal de Guatemala, donde había una guerra abierta. Tenía que elaborar un informe acerca de la relación entre el sistema penal y los derechos humanos" (Goransky, 2005, p. 993), para lo cual prosigue Maier: “Recorrí mucho, visité todas las cárceles, di varias conferencias y, finalmente, presenté cuatro recomendaciones que fueron aprobadas" (Goransky, 2005, p. 993). Tiempo después, con la constitución de una "democracia formal" en Guatemala, el presidente de la Corte Suprema de Justicia invitó a Maier a "trabajar en un proyecto jurídico de desarrollo y reforma de la administración de justicia en ese país” (Goransky, 2005, p. 993). Del mismo modo, este jurista argentino ha participado de la reforma procesal penal en $\mathrm{Chile}^{15}$, influyendo en el pensamiento de los principales referentes que impulsaron la transformación del sistema de juzgamiento penal.

15 Para mayor detalle Daniel Palacios Muñoz (2011) reconstruye desde una perspectiva sociológica la gesta de la reforma procesal penal en Chile a inicios del siglo XXI, la cual promovió un "sistema acusatorio" y se implementó en forma gradual desde el año 2000 hasta el año 2005. Es importante aclarar que a diferencia de la Argentina que se organiza con un sistema federal, Chile es un país unitario (que no cuenta con códigos provinciales). 
En reconocimiento a este recorrido y contribución, Maier es considerado como el inspirador de la reforma procesal penal latinoamericana y en estas iniciativas Alberto Binder, actual presidente del INECIP, ha sido un colaborador destacado. Por este motivo, ambos juristas han sido llamados los "padres" de los códigos procesales penales modernos en América Latina. Vale la pena tener presente que la formación de Maier en Alemania consolidó su posicionamiento en la carrera profesional gracias a la acumulación tanto de un saber específico como de un prestigio académico al haberse formado con maestros alemanes y al haberse especializado en derecho penal en uno de los lugares del mundo que se considera fuente de la disciplina. En otras palabras, el campo de la reforma de la justicia penal es también construido más allá de las fronteras nacionales "a través de las inversiones de actores insertados nacionalmente pero orientados internacionalmente" (Madsen, 2004, p. 85).

La estrategia de circulación transnacional en la formación superior radica, en primer lugar, en la obtención de credenciales educativas internacionales que legitimen el saber y, en segundo lugar, en la constitución de redes transnacionales que acrecientan el capital simbólico de los expertos en derecho, teniendo en cuenta, ante todo, la valoración del pensamiento jurídico alemán en el contexto nacional y regional. Esta circulación se complementa con el trabajo fuera del país, lo cual fortalece el nombre del jurista y continúa acrecentando su capital simbólico. Todos estos elementos están presentes en las trayectorias modelares de Levene (h.) y Maier. Merece la pena recalcar que, para el caso argentino, esta circulación internacional tuvo en parte como contexto la interrupción del orden constitucional y la eliminación del estado de derecho a partir del golpe de Estado del 24 de marzo de 1976.

\subsection{Hacer el derecho: La fuerza del derecho penal comparado}

Levene (h.) y Maier durante sus prolíferas vidas como hacedores del derecho y de la justicia además de dictar sentencias y redactar códigos, fundaron instituciones vinculadas al derecho penal desde su perspectiva comparada. Toda esta labor logró tanto impulso como legitimidad por medio del derecho penal comparado, al ser esta una disciplina fuente de sus obras. El derecho penal comparado se focaliza en el estudio del derecho en un conjunto de países para lo cual la traducción de las normas 
legales se vuelve una herramienta tan fundamental como imprescindible. No obstante, como sostiene Lena Foljanty (2016), toda traducción conlleva una cuota de creatividad y de aplicación local que es preciso considerar para un mayor entendimiento del fenómeno en términos socio-legales. En el mundo del derecho se suele hablar del derecho comparado como estrategia metodológica para abordar desarrollos legislativos fuera del país. Esta práctica les permite a los expertos estudiar los cambios legislativos en otras partes del mundo para impulsar reformas y dar cuenta de las influencias que han recibido en sus propias elaboraciones. Resta señalar que esta dinámica en medio de disputas por la imposición de las ideas legales, puede tornarse en que para algunos una reforma se sustente en el derecho comparado por medio el estudio de las tradiciones legales extranjeras y de allí se justifique la modernidad y progreso, mientras que para sus competidores esta operación se reduzca a una mera copia de ordenamientos de terceros países sin ningún valor académico ni aporte en materia de innovación jurídica.

Tanto Levene (h.) como Maier han estado vinculados al derecho penal alemán y a numerosas de sus instituciones y representantes. Ente ellos se destaca el Max-Planck-Institut für ausländisches und internationales Strafrecht, institución muy prestigiosa en el mundo del derecho penal, localizado en la ciudad de Freiburg en Alemania. La familiaridad de ambos juristas con la tradición académica germana insinúa una fuerte contribución al entendimiento de Levene (h.) y Maier acerca de la importancia del derecho penal comparado, disciplina cuyo origen se sitúa principalmente en Alemania. En esta línea no sorprende que Levene (h.) y Maier hayan participado en la gesta de instituciones abocadas al derecho penal comparado en su país de procedencia, como así también la influencia del derecho penal comparado en sus proyectos de reforma.

Levene (h.) en 1970 funda el Instituto de Derecho Penal Comparado en la Facultad de Derecho de la Universidad Católica de La Plata (UCLP), en la ciudad capital de la Provincia de Buenos Aires, institución caracterizada por constituir un polo académico de excelencia y gran relevancia en la Argentina. Años más tarde, Levene (h.) y Levene (n.) resaltarán que este instituto se trataba del "único dedicado a esta actividad específica y que, como suplemento de 'Doctrina Jurídica', publicó varios números de un boletín, en donde aparecieron valiosos 
artículos y traducciones de legislación extranjera (Brasil, Alemania Oriental, etc.)" (1982, p. 7). Esta acción de creación institucional se forjó con el espíritu de contribuir al avance del derecho penal comparado en tanto referencia necesaria para la elaboración de las reformas de la justicia. De acuerdo con Levene (h.) y Levene (n.) (1982), la creación de este instituto resulta una expresión de la vigencia de estrategias de importación del derecho en tanto relatan que:

nos inspiramos en la obra que en su Instituto de Paris lleva realizada el eminente profesor Marc Ansel; en el Max Planck Institute de Freiburg, que dirige el profesor Hans-Heinrich Jescheck, y en el Criminal Law Education and Research Center (Clear Center), organizado en la New York University School of Law por el profesor Gerhard Muller, de cuya cátedra somos profesor visitante permanente (sic.). (p. 7).

Levene (h.) en forma complementaria, expone que en la última institución mencionada se lleva adelante el Comparative Criminal Law Project, gracias al cual se traducen al inglés y publican códigos penales y procesales penales de distintos países del mundo y donde logró incluir en la serie al Código Penal de la Nación Argentina. También estaba en tratativas de publicación el Código Procesal Penal Tipo, que se había aprobado por unanimidad en el IV Congreso Nacional de Derecho Procesal organizado en Mar del Plata en 1965 (Levene (h.) \& Levene (n.), 1982), el cual ya había logrado ser publicado en Alemania con una advertencia de Levene (h.) y un trabajo introductorio de ErnstJürgen Riegger, a quien consideraba su discípulo.

Este jurista destaca que se dedicó al derecho penal comparado y a otras ciencias penales comparadas "porque los mismos facilitan el perfeccionamiento de la propia legislación" (Levene (h.) \& Levene (n.), 1982, p. 7). En la línea de trabajo derecho penal comparado Levene (h.) agrupa diversas obras suyas, entre las que se destacan Los códigos penales latinoamericanos en colaboración con Eugenio Raúl Zaffaroni -en 4 volúmenes-, Las ciencias penales en los EE.UU y el Estado actual de las ciencias penales en Costa Rica. Se trata de una "labor comparatista" vinculada a "la labor de lege ferenda"16 que "tropieza a menudo

16 Es una locución latina que significa "para una futura reforma de la ley", "en vistas a una ley futura" o "con motivo de proponer una ley". 
con el grave inconveniente que representa la dificultad de encontrar el material que necesita" (Levene (h.) \& Levene (n.), 1982, p. 9). Por ese motivo, Levene (h.) afirma: "hemos querido difundir lo que hemos aprendido al conocer la realidad alemana en el área de las ciencias penales y mostrar el nivel que han alcanzado en ese país" (Levene (h.) \& Levene (n.), 1982), p. 9) en materia tanto de derecho penal y derecho procesal penal como la criminología y el derecho penitenciario.

Asimismo, los autores aclaran que todas estas referencias se realizan "sin olvidar que esas ciencias penales son una de las más adelantadas del mundo entero y que en ellas se inspiran en buen grado los proyectos y reformas argentinos" (Levene (h.) \& Levene (n.), 1982), p. 10). En su mención a la reforma alemana, Levene (h.) se detiene en dar cuenta de los avances técnicos jurídicos y también de las formas en que se logró realizar la labor de creación legislativa por medio de comisiones y el trabajo de académicos. Esta visión expone que se precisa no solo del texto de una ley para emprender una reforma de la justicia sino que resulta imprescindible saber hacer una reforma legal en términos políticos.

$\mathrm{Al}$ analizar la trayectoria de Levene (h.), resulta muy notorio su activismo en la creación tanto de instituciones como de espacios de intercambio y reflexión en torno al derecho penal y la criminología, ya sea a nivel nacional o internacional. En esta línea, fue fundador y director de la Revista Argentina de Ciencias Penales (1975), fundador y presidente de la Sociedad Panamericana de Criminología (1979) y fundador y presidente del Centro de Estudios del Derecho Procesal Penal (1994) (CV Levene).

Casi dos décadas después de la fundación del Instituto de Derecho Penal comparado platense, en 1989, Maier -junto a una treintena de colegas y un grupo de sus discípulos- participa de la gesta de creación del INECIP. El acto fundacional instituye al INECIP con un nombre diferente al cual es conocido actualmente, originariamente nombrado como Instituto de Estudios Comparados en Ciencias Penales, de allí surge la sigla que aún a la fecha utilizan. Más tarde, se agregará a su denominación la última parte del nombre incluyendo a las Ciencias Sociales. Esta modificación se traduce en que, como adelantó, se haya convertido en el Instituto de Estudios Comparados en Ciencias Penales y Sociales. Esto da cuenta de un cambio de percepción sobre la ins- 
cripción del derecho en el campo de las ciencias y su reivindicación de las ciencias sociales para el cumplimiento de los objetivos institucionales propuestos.

La tradición cordobesa de Maier también lo vinculaba con institutos de este tipo ya que en su juventud había participado del Instituto de Derecho Penal Comparado en la Universidad Nacional de Córdoba (UNC) dirigido por Ricardo Núñez. Esta experiencia también pudo haber contribuido en la inspiración de esta gesta. Alberto Binder plantea que el surgimiento del INECIP viene de la "memoria de los mayores", es decir, que se denominó instituto porque, de hecho, "podría ser un departamento en la Universidad de Buenos Aires (UBA)" pero que ahí "no tenían donde sentarse" y de allí surge la iniciativa de crear su propia institución (Entrevista, 2012). Esta situación remite a un particular contexto histórico, ya que el INECIP se crea como fundación el 10 de mayo de 1989, en un marco de fuerte crisis socio-económica en el país dada la hiper-inflación que afectaba la economía y la profunda crisis institucional que desgastó al gobierno del primer presidente, Raúl Alfonsín (Unión Cívica Radical, UCR), elegido democráticamente luego de la dictadura militar (1976-1983).

El trabajo de codificación de los "padres de la reforma" constituye un punto nodal en las trayectorias de estos juristas y reformadores. Tanto Maier como Levene (h.) se embarcaron en la tarea de escritura de proyectos de códigos para distintas jurisdicciones. Como se muestra aquí, esta forma particular de compromiso con el derecho insumió gran parte de sus esfuerzos y trabajo a lo largo de sus vidas. El terreno legislativo representa otro gran espacio de creación del derecho y, por ese motivo, una dimensión clave para analizar la acción de estos profesionales.

Levene (h.), además de autor del Proyecto de reforma del Código Procesal Penal de la Nación, elaboró un Proyecto de Código Penal (1953) escrito en colaboración con Francisco Laplaza y Horacio Maldonado por encargo del Gobierno Nacional vía la Comisión Nacional de Legislación Penal -tal se detalla en su CV. Este proyecto fue presentado ante el Ministerio de Justicia durante la segunda presidencia de Juan Domingo Perón, sin que se lo remitiera al Congreso de la Nación. Levene (h.), en sus fundamentos puntualiza que esta iniciativa se inscribía dentro del "criterio defensista" con el propósito de "conciliar los 
derechos de la sociedad, alarmada por el delito que la hiere, con los derechos de los individuos, que aún en el caso del delincuente, tiene derechos" (López Camelo \& Jarque, 2004, p. 49). Levene (h.) en su incansable trabajo elaboró unos 16 códigos procesales provinciales en la Argentina, el primero para La Pampa en 1964 y luego se extendió a colaborar con otras provincias (Entrevista Levene (n.), 2013).

El vínculo de Maier con la elaboración de códigos se inició tempranamente mientras era alumno del profesor Jorge "Payo" Clariá Olmedo: "con quien hicimos un trabajo de fichaje del código de Córdoba y de códigos de otras provincias que le sirvió al 'Payo' para escribir esa obra monumental que hizo" (Goransky, 2005, p. 978). Estas inserciones le facilitaron a Maier mantener desde su juventud una relación estrecha con la tradición procesalista penal y reformadora de la justicia de su tierra de origen, la Provincia de Córdoba. Es relevante tener presente que esta provincia mediterránea cuenta con orgullo con una tradición académica más antigua que la proveniente de la propia capital de la República Argentina. En forma destacada, la Universidad Nacional de Córdoba (UNC) ha sido epicentro de hechos trascendentes en la historia del país como la Reforma Universitaria de 1918, protagonizada por un movimiento juvenil para democratizar la universidad y otorgarle carácter científico ${ }^{17}$. En base a esta historia, se han mantenido disputas simbólicas en torno al saber jurídico al discutir desde Córdoba el llamado centralismo porteño y su pretensión hegemónica en el campo jurídico.

Maier se reconoce discípulo de Alfredo Vélez Mariconde, fallecido en 1972. Vélez Mariconde junto a Sebastián Soler fueron los autores del Código Procesal Penal de la Provincia de Córdoba ${ }^{18}$ en 1938. Relatan Maier y Struensee (2000) que esta obra "se enfrentó con el Código de procedimientos en materia penal federal, que conservaba la legisla-

\footnotetext{
17 Esta reforma consagró la autonomía universitaria, el cogobierno, la extensión universitaria, la periodicidad de las cátedras, los concursos de oposición y la gratuidad de la enseñanza universitaria.

18 El código cordobés fue promulgado en 1939 y puesto en funcionamiento en 1940, dado que la Argentina es un país federal donde las reglas del procedimiento penal o civil corresponden a la competencia legislativa de los parlamentos provinciales, para mayor detalle de este proceso ver el texto de Cesano (2017). Un año más tarde estos autores darían a conocer el Proyecto de Código Procesal Penal para la Capital Federal, el cual fue presentado ante la Cámara de Diputados por su integrante José Peco (Levaggi, 2012).
} 
ción inquisitiva española, y determinó en la Argentina una verdadera lucha de escuelas académicas, con pretensiones legislativas y de vigencia práctica" (p. 25). La autoría de este Código provincial le significó a Vélez Mariconde un gran prestigio como el procesalista más destacado de la escuela cordobesa y, en función de este reconocimiento, también promovió proyectos de códigos en diversas provincias del país y a nivel federal. Esta recreación histórica permite vislumbrar que Maier continuó un proyecto que había sido iniciado por sus antecesores de la escuela procesal cordobesa, a cuyo linaje se remite y en la que su pensamiento se dirige como fuente para nutrirse a lo largo de su vida profesional.

En el marco del Instituto Iberoamericano de Derecho Procesal, Maier obtuvo su "primer contacto con la reforma de la justicia penal en América Latina" (Goransky, 2005, p. 991) en el proceso de elaboración del Código Procesal Penal Modelo para Iberoamérica (CPPMI) ${ }^{19}$. Esta iniciativa expresa las estrategias, en este caso, de exportación del derecho nacional a distintos países de América Latina sobre la base de la notoriedad de figuras clave del derecho local. Maier recuerda que: "Durante algunos años habían sido llevadas a cabo reuniones en las que fueron preparadas las bases de un código modelo para América Latina y elaborados algunos informes, como, por ejemplo, el Informe para un código Modelo para América Latina presentado por Vélez Mariconde y Clariá Olmedo" (Goransky, 2005, p. 991). Más tarde se presentaron "unas Segundas Bases, que representaban prácticamente el Código íntegro, trabajo elaborado por Clariá Olmedo (Goransky, 2005, p. 991).

Maier participaba de la elaboración de ese Código cuando recibió "una carta de Fernando de la Rúa" (Goransky, 2005, p. 991) político de la Unión Cívica Radical (UCR) que años más tarde llegó a ocupar la Presidencia de la Nación y quien es también jurista originario de la Provincia de Córdoba en la cual le solicitaba "que prepara un informe para presentar en una de las reuniones de preparación del Código Modelo que se iba a realizar en Guatemala, en el año 80/81" (en Goransky,

19 Este código recepta la modalidad de los códigos tipo como el que previamente había elaborado Levene (h.) para la Argentina. Se trata de modelos académicos ensayados a partir de criterios considerados científicos para la superación de la legislación vigente. 
2005, p. 991). Gracias a esta invitación, Maier trabajó en la redacción "de aquellos que podían ser llamados los 100 artículos del Código Modelo" (Goransky, 2005, p. 991) y lo presentó en Guatemala. "A partir de ese momento empecé a tener algún predicamento en América Latina", concluyó Maier (Goransky, 2005, p. 991).

En la reunión para la elaboración del Código modelo que tuvo lugar en Guatemala, Maier conoció a quien tiempo después sería el presidente de la Corte Suprema de Costa Rica, fue esta misma persona la que cursó una invitación a su país al año siguiente y lo contrató para realizar trabajos en pos de la transformación de la justicia penal mediante reformas al Código penal (Goransky, 2005, pp. 991-992). También Maier tuvo un rol protagónico en la escritura del Código Procesal Penal en Guatemala, el cual generó "la onda" a partir de la cual "con proyectos similares primero en los países centroamericanos, hoy vigentes (...) se trasladó a Sudamérica un poco más tarde" (Goransky, 2005, p. 993). Maier considera que su mayor obra, en términos de elaboración intelectual, fue el Proyecto de Código Procesal Penal para la Ciudad Autónoma de Buenos Aires (Entrevista, 2012), teniendo en cuenta el proceso de síntesis y condensación de su pensamiento a lo largo de varias décadas. Resalta el jurista que si bien no logró presentarse como proyecto legislativo para promover un nuevo Código, a pesar de haber sido convocado como redactor por poder ejecutivo local, se plasmó luego como un aporte académico al presentarse como modelo en el tercer tomo de su Manual de Derecho Procesal Penal (Maier, Entrevista, 2012). Una vez más Maier confía para transformar la justicia penal en el poder del saber académico y en el legado de su labor docente, tarea a la que se abocó con suma pasión durante toda su vida.

\section{Conclusiones: La consagración en el mundo del derecho}

Levene (h.) y Maier han sorteado los embates de tiempos políticos dramáticos durante la última dictadura militar en la Argentina, que han colisionado sus trayectorias vitales con influencia determinante en la transnacionalización de sus biografías. Ambos se caracterizan por estar investidos de máxima autoridad para definir el derecho y sus reformas gracias a sus trayectorias modelares que en forma destacada incluyen sus posiciones como encumbrados profesores y jueces en 
máximos tribunales del país. De allí emana la capacidad de decir el derecho, la cual repercute en las formas del ejercicio de la profesión y en el lugar de los abogados en el campo de poder del Estado. Este grupo de abogados detentan el monopolio de los juicios expertos sobre la reforma y son reconocidos como los voceros autorizados de la causa reformadora. No resulta casual que las trayectorias de todos ellos se ajustan a la definición socialmente aceptada de una "buena carrera" dentro del mundo del derecho, en tanto que empresa científica cristalizada en roles simultáneos en el espacio académico y de la justicia, aunque debe señalarse que se requieren también vínculos clave en el espacio político y en el mundo.

En estas páginas se mostraron los atributos que detentan ambos "reformadores", entendidos como agentes, la manera en que se diferencian y construyen sus espacios como hacedores del derecho y en consecuencia de la justicia. Levene (h.) y Maier aparecen posicionados en lugares antitéticos del universo de la reforma de la justicia penal a raíz de la competencia de sus proyectos y de algunas diferencias jurídicas, ya que el primero mantuvo una primera etapa del proceso penal federal escrita mientras que el segundo bregaba por una total oralidad de dicho proceso de juzgamiento. Sin embargo, a partir del análisis sociológico de sus trayectorias se visibilizan sus grandes afinidades y proximidades, con una fuerte incidencia de la dimensión internacional en su proyección como impulsores de la reforma de la justicia penal. En esta línea de pensamiento, el análisis de trayectorias resulta altamente productivo al contribuir en la desnaturalización de los vínculos entre los agentes y sus posiciones en el campo jurídico.

El análisis de las trayectorias de Levene (h.) y Maier también resulta un aporte sustantivo para visibilizar tanto el impacto de la esfera transnacional en la circulación de las ideas jurídicas como la constitución de los procesos de reforma normativa en materia penal a nivel local con su repercusión directa en la transformación en la persecución penal estatal. Los múltiples diálogos trasnacionales del derecho penal generados en la concepción del derecho comparado de los juristas aquí presentados, tal como se aprecia con relación a los diferentes proyectos y códigos, resultan constituyentes del propio campo de la reforma procesal penal. Allí radica la relevancia de observar la circulación internacional en la formación, los intercambios de los referentes locales con la 
academia fuera del país, los trabajos de traducción e importación/exportación del saber jurídico y la vocación por el derecho penal comparado. Este abordaje permite dimensionar el valor simbólico otorgado a la creación de instituciones que se abocan a la tarea del derecho penal comparado, lo cual significa la ocasión tanto de fortalecer y reproducir su visión del derecho como de promover su transformación de acuerdo con el propio desarrollo del derecho a nivel internacional.

Al mismo tiempo, el derecho extranjero significa la oportunidad de legitimar la movilización de reformas locales en competencia con otras tradiciones jurídicas contrincantes. Esto se evidencia con claridad en el caso argentino aquí expuesto, en el que se verifica una lucha, planteada por los "reformadores" contra el "sistema inquisitivo" vinculado al derecho español. La crítica central de este derecho es representar para sus contrincantes un derecho colonial que precisaba ser superado en pos de construir las bases de un derecho republicano y progresista. La solución esbozada por estos expertos pregoneros de la reforma en el "sistema acusatorio" encuentra su fundamento teórico en la reforma gestada en Alemania en 1975, la cual resultó introducida localmente gracias a la traducción realizada por Maier. La traducción del derecho alemán, y su importación, se re-significa en tanto búsqueda de un derecho nacional diferenciado del derecho español, cuestión sensible por razones históricas y políticas en toda la denominada Hispanoamérica.

Este mecanismo reformador de la justicia penal generado por los expertos del derecho, en este caso jueces y profesores, a partir de su circulación internacional resulta ser cristalizado en propuestas normativas de nuevos códigos de derecho procesal penal a nivel federal, ya sea en la Argentina como en la región latinoamericana. Estas reformas en la justicia, en la historia nacional, se han puesto en juego en el sistema legislativo con la pretensión de plasmar las bases para un nuevo modelo que democratice y humanice el enjuiciamiento penal estatal de los crímenes federales de gran trascendencia pública e impacto en el gobierno de la República Argentina. Es en este punto donde se vuelve significativo el estudio de las trayectorias y las redes de los profesionales del derecho, para (re)pensar la transformación del poder del Estado a partir de los propios agentes. Esta tarea se emprende desde una perspectiva sociológica que busca reconstruir las dinámicas de formación, vinculación internacional y despliegue de las posiciones públicas de 
los agentes que constituyen estos profundos cambios del derecho y la justicia en nuestras sociedades.

Con esta mirada, a lo largo de las páginas precedentes, se han logrado reestablecer algunos de los recorridos personales y de las estrategias desarrolladas por los jueces "padres de la reforma" para gestar e impulsar los procesos de transformación del procedimiento penal federal en la Argentina. Esta experiencia de investigación comprueba cómo el estudio de las trayectorias de los agentes facilita comprender al mismo tiempo su capacidad de transformación del derecho y el despliegue de los ordenamientos jurídicos. El cambio del ordenamiento del procedimiento procesal penal en la República Argentina en el siglo XX fue posible gracias a la labor incansable de Levene (h.) y Maier quienes fueron juristas consagrados en el mundo del derecho; consagraciones construidas con fuerza por el capital simbólico originado en su posición de jueces a lo largo de sus vidas.

\section{Referencias}

Agrikoliansky, É. (2001). Carrières militantes et vocation à la morale: Les militants de la ligue des droits de l'homme dans les années 1980. Revue Française de Science Politique, 51(1-2), 27-46.

Bancaud, A. \& Dezalay, Y. (1984). La sociologie juridique comme enjeu social et professionel. Revue Interdisciplinarie D'Études Juridiques, (12), 1-29.

Becker, H. (2010). Outsiders: Hacia una sociología de la desviación. Buenos Aires: Siglo XXI.

Binder, A. (1993). Crisis y transformación de la justicia penal en Latinoamérica. En Binder, A. et. al., Reformas procesales en América Latina. La oralidad de los procesos (pp. 67-88). Santiago de Chile: Corporación de Promoción Universitaria.

Bourdieu, P. (1991). Les juristes les gardiens de l'hypocrisie collective. En F. Chazel \& J. Commaille (Dir.), Normas juridiques et régulation sociale. Collection Droit et société (pp. 65-99). Paris: Libraire Générale de Droit et de Jurisprudence.

Bourdieu, P. (1996). A economia das trocas lingüisticas. O que falar quer dizer. São Paulo: Editora da Universidade de São Paulo.

Bourdieu, P. (1998). Intelectuales, política y poder. Buenos Aires: Editorial Universitaria de Buenos Aires. 
Bourdieu, P. (2000). Elementos para una sociología del campo jurídico. En P. Bourdieu y G. Teubner, La fuerza del derecho (pp. 153220). Bogotá: Uniandes.

Bourdieu, P. (2011). La ilusión biográfica. Acta Sociológica, (56), 121-128. Bovino, A. (1993). El debate. En J. Maier (Comp.), El nuevo Código Procesal Penal de la Nación: Análisis crítico (pp. 167-195). Buenos Aires: Editores del Puerto.

Cesano, J. (2017). Contexto político, opinión pública y perfiles intelectuales en el proceso de codificación procesal penal de la provincia de Córdoba (1937-1939). Córdoba: Lernier.

Córdoba, F. (1993). La posición de la víctima. En J. Maier (Comp.), El nuevo Código Procesal Penal de la Nación: Análisis crítico (pp. 81-101). Buenos Aires: Editores del Puerto.

Córdoba, G. (2010). Introducción. En D. Pastor, P. Ziffer, E. Sarrabayrouse, M. Sancinetti, G. Córdoba (autores), Reflexiones sobre el procedimiento penal. Una tarde con Julio Maier (pp. 12-17). Buenos Aires: Ad-Hoc.

Dezalay, Y. \& Garth, B. (1998). From notables of the foreign policy establishment to the international market of professionals of philanthropy and human rights: Strategies for power and the social construction of a new field of state expertise. American Bar Foundation: Working Papers Series, (9.818), pp. 1-84.

Dezalay, Y. \& Garth, B. (2003). The internationalization of palace wars: Lawyers, economists, and the contest to transform Latin American states. Chicago: The University of Chicago Press.

Donatello, L. \& Lorenc Valcarce, F. (2016). El ascenso a la elite judicial. Una reconstrucción de los orígenes y las trayectorias de los jueces a partir de entrevistas biográficas. Revista Argentina de Sociología, 11(19-20), 6-29.

Duve, T. (2016). Global legal history - A methodological approach. Max Plack Institute for European Legal History, Research Paper Series, (2016-04), 1-23.

Engelmann, F. (2006). Sociologia do campo jurídico. Porto Alegre: Fabris.

Ferrari, M. (2010). Prosopografía e historia política. Algunas aproximaciones. Antítesis, 3(5), 529-550.

Fillieule, O. (2001). Prepositions pour une analyse processuelle de l'engagements individuel. Revue Française de Science Politique, 51(1-2), 199-215. 
Fillieule, O. (2010). "Tombeau pour Charles Tilly". Répertoires, performances et strátegies d'action. En É. Agrikoliansky, I. Sommier y O. Fillieule (Dirs.), Penser les mouvements sociaux. Conflicts sociaux et contestations dans les sociétés contemporaines (pp. 77-99). Paris: La Découverte.

Fillieule, O. (2015a). Carrière militante. En O. Fillieule, L. Mathieu y C. Péchu (Dirs.), Diccionnaire des mouvementes sociaux (pp. 85-94). Paris: Presses de Sciences Po.

Fillieule, O. (2015b). Mobilisation des ressources. En C. Le Digol (Dir.), Dictionnaire de sociologie. Paris: Albin Michel, Encyclopaedia Universalis.

Foljanty, L. (2016). Translators, mediators of legal transfers. Rechtsgeschichte Legal History, (24), 120-121.

Gaïti, B. \& Israël, L. (2003). Sur l'engagement du droit dans la construction des causes. Politix. Revue des Sciences Sociales du Politique, 62(2), 17-30.

Goransky, M. (2005). Entrevista al Profesor Julio B. J. Maier. En B. Baigún (Coord.), Estudios sobre justicia penal. Homenaje al profesor Julio B. J. Maier (pp. 975-996). Buenos Aires: Editores del Puerto.

Guber, R. (1991). El salvaje metropolitano. A la vuelta de la antropología postmoderna. Reconstrucción del conocimiento social en el trabajo de campo. Buenos Aires: Legasa.

Gutiérrez, A. (2010). A modo de introducción. Los conceptos centrales en la sociología de la cultura de Pierre Bourdieu. En P. Bourdieu (Autor), El sentido social del gusto. Elementos para una sociología de la cultura (pp. 9-18). Buenos Aires: Siglo XXI.

Israël, L. (2001). Usages militants du droit dans l'arène judiciare: le cause lawyering. Droit et Societè, 49(3), 793-824.

Jescheck, H. (1982). Los rasgos fundamentales del movimiento internacional de reforma del derecho penal. Barcelona: Bellaterra.

Langer, M. (2007). Revolution in Latin American criminal procedure: Diffusion of legal ideas from the periphery. American Journal of Comparative Law, 55(4), 617-677.

Langer, M. (2014). La larga sombra de las categorías acusatorio-inquisitivo. Derecho Público, (32), 1-34.

Levaggi, A. (2012). El derecho penal argentino en la historia. Buenos Aires: Editorial Universitaria de Buenos Aires. 
Levene (h.), R. (1989). Proyecto de Código procesal penal para la capital federal y justicia federal. Buenos Aires: Depalma.

Levene (h.), R. (1993). Manual de Derecho Procesal Penal. (Tomo I). Buenos Aires: Ediciones Depalma.

Levene (h.), R. \& Levene (n.), R. (1982). Las ciencias penales en la República Federal de Alemania. Buenos Aires: Editorial Universidad.

López Camelo, R. \& Jarque, G. (2004). Curso de Derecho Penal. Parte General. Bahía Blanca: Editorial de la Universidad Nacional del Sur.

Madsen, M. (2004). France, the UK and "boomerang" of the internationalisation of human rights (1945-2000). En S. Halliday y P. Smith (Eds.), Human rights brought home: Socio-legal perspectives on human rights in the national context (pp. 57-86). Oxford: Hart.

Madsen, M. (2006). Transnational fields: Elements of a reflexive sociology of the internationalisation of law. Retfoerd. Nordisk Juridisk Tidsskrift, 29(3/114), 23-41.

Maier, J. (1978). La ordenanza procesal penal alemana. Su comentario y comparación con los sistemas de enjuiciamiento penal argentinos (Vol. I). Buenos Aires: Ediciones Depalma.

Maier, J. (1987). Presentación. En J. Maier (Autor), Proyecto de Código procesal penal de la nación. (Cuadernos de la revista doctrina penal. teoría y práctica en las ciencias penales) (pp. 645-670). Buenos Aires: Argent Consult.

Maier, J. (1989). Derecho procesal penal argentino. Buenos Aires: Hammurabi.

Maier, J. (1993a). Democracia y administración de justicia penal en Iberoamérica: los proyectos para la reforma del sistema penal. En A. Binder, J. Maier, C. Riego (Eds.), Reformas procesales en América Latina. La oralidad de los procesos (pp. 67-88). Santiago de Chile: Corporación de Promoción Universitaria.

Maier, J. (1993b). El nuevo Código Procesal Penal de la Nación: Análisis crítico. Buenos Aires: Editores del Puerto.

Maier, J. (1996). Derecho procesal penal. Fundamentos. (Tomo 1). Buenos Aires: Editores del Puerto.

Maier, J. (2003). Prólogo. En J. Woischnik (Autor). Juez de instrucción y derechos humanos en Argentina. Un análisis crítico del Có- 
digo Procesal Penal de la Nación (pp. 20-21). Buenos Aires: Konrad Adenauer Stiftung \& Ah-Hoc.

Maier, J. \& Struensee, E. (2000). Introducción. En J. Maier, K. Ambos \& J. Woischnik (Coords.), Las reformas procesales penales en América Latina (pp. 17-32). Buenos Aires: Ad-Hoc.

Mira, J. (2017). Una promesa de democratización. Activismo, política y expertise jurídica en el proceso de reforma de la justicia penal en la Argentina (Tesis doctoral inédita). Facultad de Ciencias Sociales de la Universidad de Buenos Aires, Buenos Aires.

Mira, J. (2019). Follow the actors: Ethnographic keys for understanding legal activism for criminal justice reform in Argentina. The Age of Human Rights Journal, (13), 63-74.

Mira, J. (2020). Cosmologies of federal criminal procedural reform: Democratizing and humanizing criminal justice in Argentina. En P. Ciocchini \& G. Radics (Eds.), Criminal legalities in the global south. Cultural dynamics, political tensions, and institutional practices (pp. 105-123). Abingdon/Nueva York: Routledge.

Palacios Muñoz, D. (2011). La reforma procesal en Chile: Nuevos agentes, sus trayectorias y la reestructuración de un campo. Revista Política, 49(1), 43-70.

Pastor, D. (2009). El futuro de la reforma procesal penal en la Argentina y el aporte de la experiencia alemana. En H. Albrecht, U. Sieber, J. Simon, \& F. Schwarz (Eds.) Criminalidad, evolución del derecho penal y crítica al derecho penal en la actualidad. Simposio argentino-alemán (pp. 159-170). Buenos Aires: Editores del Puerto.

Sawicki, F. \& Siméant, J. (2009). Déscloisonner la sociologie de l'engagement militante. Note critique sur quelques tendendes récentes des travaux français. Sociologie du Travail, 51(1), 97-125.

Tau Anzoátegui, V. (1977a). La codificación en la Argentina 1810-1870. Mentalidad social e ideas jurídicas. Buenos Aires: Imprenta de la Universidad.

Tau Anzoátegui, V. (1977b). Las ideas jurídicas en la Argentina (Siglos $X I X-X X)$. Buenos Aires: Perrot.

Vauchez, A. \& Willemez, L. (2007). La justice face à ses réformateurs (1980-2006). Enterprises de modernisation et logiques de résistances. Paris: Presses Universitaries de France. 
Vecchioli, V. (2011). Presentación: Profesionales del derecho, activismo jurídico y creación de nuevos derechos. Hacia una mirada comprensiva del derecho desde las ciencias sociales. Revista Política, 49(1), 5-18.

Woischnik, J. (2003). Juez de instrucción y derechos humanos en Argentina. Un análisis crítico del Código Procesal Penal de la Nación. Buenos Aires: Konrad Adenauer Stiftung \& Ah-Hoc.

\section{Fuentes}

CV Ricardo Levene (h.), mimeo.

CV Ricardo Levene (h.), síntesis en inglés, mimeo.

CV Julio Maier, Facultad de Derecho - UBA, disponible en línea.

Entrevista, Alberto Binder, Ciudad Autónoma de Buenos Aires, 6 de octubre 2011.

Entrevista, Ricardo Levene (n.), Ciudad Autónoma de Buenos Aires, 3 de noviembre de 2013.

Entrevista, Julio Maier, Victoria, Provincia de Buenos Aires, 2 de junio de 2012.

Legajo docente, Ricardo Levene (h.), Museo de la Facultad de Derecho, UBA.

Legajo docente, Manuel Obarrio, Museo de la Facultad de Derecho, UBA. 


\section{Anexo 1}

Codificación procesal penal federal aprobada en la Argentina

\begin{tabular}{|c|c|c|c|c|}
\hline $\begin{array}{c}\text { Fecha } \\
\text { aprobación }\end{array}$ & Ley $\mathrm{N}^{\circ}$ & $\begin{array}{c}\text { Denominación } \\
\text { Código }\end{array}$ & $\begin{array}{l}\text { Conocido } \\
\text { como }\end{array}$ & Presidencia \\
\hline $\begin{array}{l}4 \text { de octubre } \\
\text { de } 1888\end{array}$ & 2372 & $\begin{array}{l}\text { Código de } \\
\text { Procedimientos en } \\
\text { lo Criminal (CPC). } \\
\text { Proyecto elaborado } \\
\text { por Manuel Obarrio } \\
\text { en } 1882 .\end{array}$ & $\begin{array}{l}\text { "Código } \\
\text { Obarrio" }\end{array}$ & $\begin{array}{l}\text { Miguel Ángel } \\
\text { Juárez Celman, } \\
\text { Partido } \\
\text { Autonomista } \\
\text { Nacional } \\
\text { (PAN). }\end{array}$ \\
\hline $\begin{array}{l}21 \text { de agosto } \\
\text { de } 1991\end{array}$ & 23984 & $\begin{array}{l}\text { Código Procesal } \\
\text { Penal de la Nación } \\
\text { (CPPN). Proyecto } \\
\text { elaborado por } \\
\text { Ricardo Levene } \\
\text { (h.) en su primera } \\
\text { versión en } 1975 \\
\text { presentado en el } \\
\text { Senado por José H. } \\
\text { Martiarena y Alfredo } \\
\text { L. Benitez y luego } \\
\text { actualizado en } 1989 .\end{array}$ & $\begin{array}{l}\text { "Código } \\
\text { Levene" }\end{array}$ & $\begin{array}{l}\text { Carlos Saúl } \\
\text { Menem, } \\
\text { Partido } \\
\text { Justicialista } \\
\text { (PJ). }\end{array}$ \\
\hline \multirow[t]{2}{*}{$\begin{array}{l}4 \text { de } \\
\text { diciembre } \\
\text { de } 2014 \\
\text { (vigente } \\
\text { desde el } 10 \\
\text { de junio de } \\
\text { 2019) }\end{array}$} & 27063 & $\begin{array}{l}\text { Código Procesal } \\
\text { Penal de la Nación } \\
\text { (CPPN). Proyecto } \\
\text { presentado por el } \\
\text { Poder Ejecutivo en el } \\
\text { Congreso Nacional. }\end{array}$ & & $\begin{array}{l}\text { Cristina } \\
\text { Fernández } \\
\text { de Kirchner, } \\
\text { Partido } \\
\text { Justicialista } \\
\text { (PJ) - Frente } \\
\text { por la Victoria } \\
\text { (FPV). }\end{array}$ \\
\hline & & $\begin{array}{l}\text { Resultó suspendida } \\
\text { su vigencia por el } \\
\text { DNU 257/2015. La } \\
\text { Ley N }{ }^{\circ} 27482, \text { lo } \\
\text { aprobó, modificó y } \\
\text { denominó: Código } \\
\text { Procesal Penal } \\
\text { Federal (CPPF). }\end{array}$ & & $\begin{array}{l}\text { Mauricio } \\
\text { Macri, } \\
\text { Propuesta } \\
\text { Republicana } \\
\text { (PRO) - } \\
\text { Cambiemos. }\end{array}$ \\
\hline
\end{tabular}

Fuente: Elaboración propia en base a las referencias oficiales de los códigos que se encuentran en los sitios www.infojus.gov.ar y www.infoleg.gov.ar 


\section{Anexo 2}

Proyectos de reforma procesal penal federal en la Argentina

\begin{tabular}{|c|c|c|c|c|}
\hline \multicolumn{5}{|c|}{ Proyectos Código Procesal Penal de la Nación (Argentina) } \\
\hline $\begin{array}{l}\text { Conocido } \\
\text { como }\end{array}$ & $\begin{array}{l}\text { "Proyecto } \\
\text { Levene" }\end{array}$ & $\begin{array}{l}\text { "Proyecto } \\
\text { Maier" }\end{array}$ & $\begin{array}{c}\text { "Proyecto } \\
\text { INECIP" / "Pro- } \\
\text { yecto Albrieu" }\end{array}$ & $\begin{array}{l}\text { "Proyecto } \\
\text { Beraldi" }\end{array}$ \\
\hline \multirow[t]{2}{*}{$\begin{array}{l}\text { Año y } \\
\text { versión }\end{array}$} & \multirow[t]{2}{*}{$\begin{array}{l}1989 \\
\text { (versión } \\
\text { actualizada } \\
\text { de un } \\
\text { proyecto } \\
\text { previo de } \\
1975 \text { que } \\
\text { logra ser } \\
\text { aprobado } \\
\text { en 1991). }\end{array}$} & \multirow[t]{2}{*}{$\begin{array}{l}1986 \\
\text { (elaborado } \\
\text { por la } \\
\text { comisión } \\
\text { convocada } \\
\text { por el } \\
\text { presidente } \\
\text { Alfonsín } \\
\text { con la } \\
\text { coordinación } \\
\text { de Julio } \\
\text { Maier). }\end{array}$} & $\begin{array}{l}2004 \\
\text { ("Proyecto } \\
\text { INECIP" firmado } \\
\text { por Alberto } \\
\text { Binder e Iliana } \\
\text { Arduino). }\end{array}$ & $\begin{array}{l}2007 \\
\text { (elaborado } \\
\text { por la } \\
\text { comisión } \\
\text { convocada } \\
\text { por el } \\
\text { Ministerio } \\
\text { de Justicia, } \\
\text { decreto del } \\
\text { presidente } \\
\text { Kirchner). }\end{array}$ \\
\hline & & & $\begin{array}{l}2010 \\
\text { (versión } \\
\text { actualizada que el } \\
\text { Diputado Albrieu } \\
\text { presenta en el } \\
\text { Congreso de la } \\
\text { Nación). }\end{array}$ & $\begin{array}{l}2011 \\
\text { (versión } \\
\text { actualizada). }\end{array}$ \\
\hline $\begin{array}{l}\text { Partido } \\
\text { político } \\
\text { en el } \\
\text { gobierno } \\
\text { nacional }\end{array}$ & $\begin{array}{l}\text { Partido } \\
\text { Justicialista } \\
(\mathrm{PJ}) .\end{array}$ & $\begin{array}{l}\text { Unión Cívica } \\
\text { Radical } \\
\text { (UCR). }\end{array}$ & \multicolumn{2}{|c|}{$\begin{array}{l}\text { Partido Justicialista (PJ) - Frente } \\
\text { para la Victoria (FPV). }\end{array}$} \\
\hline
\end{tabular}

Fuente: Elaboración propia a partir de los proyectos de reforma procesal penal y de acuerdo a las referencias destacadas por los "reformadores", por este motivo no se trata de una enumeración exhaustiva. 